\title{
II. Abkehr des Kabinetts Brüning von der Politik Stresemanns
}

Wenige Monate später war die Lage völlig verändert, herrschte in ganz Europa, vor allem aber in Frankreich, panische Angst vor einem neuen deutsch-französischen Krieg. In den Augen vieler schien der Krieg sogar unmittelbar bevorzustehen. Angesichts der militärischen Kräfteverhältnisse, die der trotz aller Umgehungen des Versailler Vertrags schwachen Reichswehr noch keinen Angriff auf einen der westlichen oder auch östlichen Nachbarn erlaubte, war das natürlich blanker Unsinn. Jedoch kam die Kriegsfurcht nicht von ungefähr, eine tiefgreifende und nichts Gutes verheißende Veränderung der politischen Situation hatte in der Tat stattgefunden.

Schon Ende November 1929 hatte Group Captain M. G. Christie, der Luftattaché an der britischen Botschaft in Berlin, ein Memorandum verfaßt, in dem sich nicht nur recht kritische Bemerkungen fanden über die Unfähigkeit der Deutschen, politisch zu handeln und das Reichsinteresse über Parteiinteressen zu stellen, sondern auch Beobachtungen über die Zusammenarbeit zwischen Reichswehr und Roter Armee wie über die beharrliche wenn auch noch mühselige und eingeschränkte - Arbeit am Aufbau einer deutschen Luftwaffe; „ermutigt durch die Räumung des Rheinlands, wird das Reichswehrministerium damit heimlich fortfahren “. Auch die Prognose über die künftige deutsche Polenpolitik fiel düster aus. Harold Nicolson, der das Memorandum an das Foreign Office sandte, bemerkte in seinem Begleitschreiben: „Ich stimme mit Captain Christie vollauf überein, daß das Deutsche Reich in den nächsten Jahren ein außerordentlich schwieriger Faktor in der europäischen Diplomatie sein wird."1 Solcher Pessimismus erwies sich als berechtigter denn der - freilich zurückhaltende - Optimismus, den Orme Sargent und Sir Horace Rumbold oder auch Briand an den Tag legten.

Ursache des Wandels war die innenpolitische Entwicklung in Deutschland $^{2}$. Am 27. März 1930 hatte, äußerlich gesehen, ein recht kleinlicher wenn auch durchaus ernsthafter - Streit um die Finanzierung der Arbeitslosenversicherung, ausgefochten zwischen SPD und Deutscher Volkspartei,

2 Dazu die klassische Darstellung von Bracher, Auflösung der Weimarer Republik, S. $287 \mathrm{ff}$;; ebenso Schulz, Von Brüning zu Hitler, S. 13 ff.; instruktiv und mit exzellenter Literaturübersicht Kolb, Die Weimarer Republik, hier S. $124 \mathrm{ff}$.; ferner die entsprechenden Abschnitte in der glänzenden Gesamtdarstellung von Winkler, Weimar 1918-1933, S. 363 ff. 
zum Rücktritt des von Hermann Müller, einem Sozialdemokraten, geleiteten Kabinetts der Großen Koalition aus SPD, Demokratischer Partei, Zentrum, Bayerischer Volkspartei und Deutscher Volkspartei geführt. Der eigentliche Grund lag indes darin, daß Deutsche Volkspartei, Teile des Zentrums und im Hintergrund Reichspräsident und Reichswehrführung die Teilhabe der Sozialdemokraten an der Macht wieder beenden wollten. Die politischen Gewichte in Deutschland sollten nach rechts verschoben werden, soweit es die Verfassung irgend zuließ. In der Praxis hieß das, den Reichstag zumindest partiell zu entmachten und das Deutsche Reich wie in Zeiten ernster Krisen mit Hilfe des präsidialen Notverordnungsrechts zu regieren. Reichspräsident Paul v. Hindenburg machte denn auch, als er den Zentrumsabgeordneten Heinrich Brüning mit der Kabinettsbildung beauftragte, offiziell und öffentlich klar, daß die neue Regierung nicht auf der Grundlage „koalitionsmäßiger Bindungen“ zu bilden sei ${ }^{3}$. Wie zielbewußt zu Werke gegangen wurde, zeigte nicht zuletzt die Schnelligkeit, mit der eine Regierung zustande kam, die doch faktisch eine Verabschiedung von der Weimarer Repulik war, wie sie von 1924 bis 1930 bestanden hatte. Bereits am 30. März konnte der Reichspräsident die Ernennungsurkunden der Kabinettsmitglieder unterzeichnen. Kern der neuen Regierung war das alte Kabinett. Nicht weniger als sieben Minister hatten schon der Regierung Müller angehört. Jedoch war auf der Linken die SPD weggefallen, während auf der Rechten der Deutschnationale Martin Schiele und der Volkskonservative Gottfried Treviranus hinzugekommen waren. In der Mitte saßen etliche Vertreter des Zentrums, namentlich Innenminister Joseph Wirth und der neue Reichskanzler Heinrich Brüning, die bereit waren, sich für den vor allem von Hindenburg und Reichswehr gewünschten Rechtsruck zur Verfügung zu stellen. Da es Brüning immer wieder gelingen sollte, sich für bestimmte Akte seiner Finanzpolitik die Tolerierung durch die SPD zu sichern, wurde längere Zeit verschleiert, wie groß die Entfernung zur alten Weimarer Republik nun war. Tatsächlich aber handelte es sich beim Kabinett Brüning um eine Regierung, die nicht mehr vom Vertrauen des Reichstags abhing, sondern vom Vertrauen des Reichspräsidenten, und dessen Machtbasis stellte, neben seinem Ruhm als „Sieger von Tannenberg“, die Reichswehr dar; wer mit dem Artikel 48 der Verfassung, dem Notverordnungsartikel, regierte, stützte sich letzten Endes auf die Armee.

In diesem Kabinett lag die Leitung der Außenpolitik anfänglich nahezu ausschließlich in den Händen Heinrich Brünings und des Außenministers Julius Curtius. Brüning hatte sich im Weltkrieg als Frontoffizier vielfach bewährt und war vom Erlebnis des Krieges tief geprägt worden ${ }^{4}$. Zwar hatte

3 Schulthess' 1930, S. 93.

4 Dazu vor allem Brüning, Memoiren. Conze, Brüning als Reichskanzler, und Morsey, Brüning und Adenauer, kamen in der noch längst nicht abgeschlossenen Brüning-Diskussion zu positiven Urteilen über die Politik des Reichskanzlers. Hier wird im wesentlichen die Kritik 
er sich nach dem Krieg der Zentrumspartei angeschlossen und war - auch als Geschäftsführer des christlichen Deutschen Gewerkschaftsbundes fungierend - Reichstagsabgeordneter und schon 1929 Vorsitzender der Zentrumsfraktion geworden. Auch hatte er in den Jahren seines Aufstiegs, den er nicht zuletzt hohem Fleiß und eindrucksvoller Arbeitskraft verdankte, eine stupende Sachkenntnis in sozial- und vor allem finanzpolitischen Fragen erworben. Gleichwohl hatte sich dieser westfälische Katholik soldatische Gesinnung, größten Respekt vor der preußischen Armee und die Überzeugung bewahrt, daß eine Außenpolitik, wie sie Deutschland künftig führen müsse, um mindestens die bis 1914 errungene Position wiederzugewinnen, der Deckung durch eine schlagkräftige Armee bedürfe; daß die Wiedergewinnung anzustreben sei, stand für ihn außer Zweifel. Im Rahmen solcher Vorstellungswelt erhielt die Abschüttelung der Reparationslast zwangsläufig absolute Priorität. Finanzielle Bewegungsfreiheit war unabdingbare Voraussetzung der rüstungs- und außenpolitischen Bewegungsfreiheit. Hermann Pünder, Staatssekretär in der Reichskanzlei und einer jener wenigen Mitarbeiter Brünings, die als Vertraute angesehen werden können, bescheinigte seinem neuen Chef nach kurzer Zeit, daß er „gewissen großen Zielen" nachgehe ${ }^{5}$, und das Bemühen Brünings, die Sozialdemokraten zur Tolerierung seiner Finanzpolitik zu bewegen, kommentierte er in seinem Tagebuch mit den Sätzen: „Wir können ihnen immer nur wieder sagen: wir verlangen alles und versprechen nichts! Fast nur Unpopuläres wird gefordert gegen die gewisse Sicherheit, daß dann in einem anderen Kriege Deutschland insgesamt leidlich gerüstet dastehe." 6

Die Frage, ob Brüning eine Restauration der Monarchie anstrebte, wie er in seinen Memoiren behauptet hat, kann hier beiseite gelassen werden, hingegen liegt klar auf der Hand, daß er für seine Reparationspolitik eine Finanzpolitik brauchte, die das Land an den Rand des wirtschaftlichen Zusammenbruchs steuern mußte - wie hätte er die Gläubigerstaaten sonst zum Verzicht auf deutsche Reparationen bringen sollen? - und mithin die Unabhängigkeit der Regierung vom Parlament erforderte. Liquidierung des Young-Plans, Deflationspolitik und Zurückdrängung des Reichstags, also hinter der Weimarer Fassade der allmähliche Aufbau eines autoritären Systems, hingen aufs engste zusammen. Brüning war sich nicht nur des $\mathrm{Zu}$ sammenhangs bewußt, er glaubte auch - mit Recht - die zur Exekution einer solchen Politik notwendige Härte zu besitzen; wie er als Führer einer Maschinengewehr-Kompanie an der Westfront Opfer von seinen Soldaten

akzeptiert, die Bracher bekräftigt hat: Brünings unpolitische Politik. Vgl. auch Graml, Präsidialsystem. - Die Studie von Patch, Jr., Heinrich Brüning, enthält nicht wenige sachliche Mißverständnisse bei der Interpretation deutscher Quellen. - Neuerdings die gewichtige Arbeit von Hömig, Brüning - Kanzler in der Krise der Republik.

5 Pünder, Politik in der Reichskanzlei, S. 61.

6 Ebenda, S. 91. 
verlangt hatte, so war er nun bereit, im Dienste der Sache Opfer von der ganzen Nation zu verlangen. Nicht nur das empfahl ihn Hindenburg und der Reichswehrführung. Zwei Monate vor seiner Ernennung zum Kanzler hatte er, am 11. Februar im Reichstag, unzweideutig erklärt, daß er auch zu den Gegnern der Entmilitarisierung des Rheinlands, eines wesentlichen Bestandteils der Locarno-Politik, gehöre und unnachgiebig für die Revision der deutschen Ostgrenze eintrete ${ }^{7}$.

Kein Demagoge in öffentlicher Rede, diskutierte er in Verhandlungen stets unaufgeregt und dem Anschein nach streng sachlich. So wirkte er nicht allein auf angelsächsische Gesprächspartner überaus vorteilhaft und überzeugend. Nachdem er den Reichskanzler kennengelernt hatte, schrieb Benno Reifenberg von der „Frankfurter Zeitung“ am 21. Juli 1931 in einem Privatbrief: „Brüning macht zweifellos Eindruck... Ich habe bis jetzt nur die schweren politischen Fehler des Mannes gesehen, habe aber, als ich ihn sah, gelernt, wie wichtig die persönliche Wirkung eines Staatsmannes auch heute sein kann." 8 Brüning war gewiß keine dämonische Gestalt. Aber ihm eigneten - und das zu konstatieren, heißt nicht ihn dämonisieren - Zielbewußtsein, Sinn für politische Strategie und Konsequenz.

Julius Curtius hat viele, mit denen er als Politiker zu tun hatte, ebenfalls sympathisch beeindruckt. Der britische Botschafter fand in seinen Berichten an das Foreign Office wiederholt Gelegenheit, sich rühmend zu äußern, und nachdem Curtius Anfang Oktober 1931 demissioniert hatte, schrieb Sir Horace Rumbold an Lord Reading, damals vorübergehend britischer $\mathrm{Au}$ ßenminister: „Meine Kollegen und ich bedauern Dr. Curtius' Ausscheiden aus dem Außenministerium. Zwar hatte er weder die Vorstellungskraft und den weiten Horizont noch das politische Genie seines Vorgängers, doch war er ein ausgeglichener Mann, und seine ruhige und höfliche Art machten den Umgang mit ihm angenehm. "9 Jüngere deutsche Diplomaten nannten ihn "hölzern“, „etwas phantasielos“, „anständig“, „ein bißchen naiv“, aber doch „selbstbewußt"10. Er selbst betrachtete sich als „Testamentsvollstrekker" Stresemanns, dem er, nachdem er sich als Wirtschaftsminister Meriten erworben hatte, im Amt gefolgt war. Dabei hat er seinen Parteifreund freilich verkannt. Er sah in ihm immer noch den puren Revisionisten und revisionspolitischen Taktiker, wie Stresemann es zwischen 1923 und 1927/28 ja tatsächlich gewesen war; den Wandlungsprozeß des Vorgängers hat er nicht bemerkt oder nicht verstanden ${ }^{11}$. Mit seinen eigenen Zielen war er, der sich

7 Schulthess', 1930, S. $31 \mathrm{f}$.

8 Hummerich, Wahrheit zwischen den Zeilen.

9 Rumbold an Lord Reading; DBFP, Second Series, Vol. II, Nr. 262.

10 So etwa Weizsäcker-Papiere, S. 393.

11 Rödder, Stresemanns Erbe, ist geneigt, Curtius' Selbstverständnis zu akzeptieren. Dem wird hier nicht zugestimmt. 
im parlamentarischen Getriebe des Genfer Völkerbunds nicht wohl fühlte, Revisionspolitiker reinsten Wassers ${ }^{12}$.

Curtius stimmte mit Brüning in der Reparationsfrage ebenso vorbehaltlos überein wie in der Rüstungsfrage; auch den Zusammenhang beider Probleme beurteilte er nicht anders als der Reichskanzler. Einen Unterschied gab es jedoch. Brüning war im Grunde - und mit Grund - der Meinung, daß die Revision territorialer Bestimmungen des Versailler Vertrags - gegen die natürlich unentwegt agitiert werden müsse - erst erreichbar sei, wenn hinter deutscher Außenpolitik wieder ein starkes Heer stehe. Curtius hingegen hoffte auf baldige Revisionen allein mit politischen Mitteln: Westpreußen und Posen! Oder vielleicht erst Anschluß Österreichs? Mit der Rückgliederung des Saargebiets bis zur Abstimmung im Januar 1935 warten zu müssen, dünkte ihm schier unerträglich.

Wenige Monate nach der Regierungsbildung stellte sich denn auch heraus, daß der Testamensvollstrecker Stresemanns dessen wichtigsten Gehilfen nicht mehr in Berlin und im Auswärtigen Amt zu haben wünschte. Staatssekretär v. Schubert wurde im Juni 1930 als Botschafter nach Rom versetzt, wo er Neurath ablöste, der nach London ging. Nun kommt es zu solchen Revirements nicht selten aus ganz unpolitischen Gründen. In diesem Falle aber handelte es sich nicht um einen gewöhnlichen Vorgang. Zum Nachfolger Schuberts wurde über den Kopf des Ministerialdirektors Gerhard Köpke der Vortragende Legationsrat Bernhard v. Bülow ernannt. Bülow, ein Neffe des Fürsten Bülow, der im wilhelminischen Deutschland Reichskanzler gewesen war, hatte zu den erbitterten Gegnern Stresemanns und dessen Politik gehört. Deutschlands bevorstehenden Eintritt in den Völkerbund hatte der damalige Leiter des Völkerbundsreferats im Auswärtigen Amt mit der Bemerkung kommentiert, die Vertreter Deutschlands in Genf müßten - da dort jeder deutsche Schritt mit „Argusaugen verfolgt werden wird“ und die Welt die Frage stelle, „ob wir in den letzten ... Jahren etwas hinzugelernt bzw. umgelernt haben" - die eigentlichen deutschen Bestrebungen durch Reden verschleiern, denen sie einen „salbungsvollen Ton“ zu geben hätten ${ }^{13}$. Jede Bindung an internationale Vertragssysteme oder an Frankreich, die Deutschlands revisionspolitische Bewegungsfreiheit behindern mochten, war ihm verhaßt. Der Eckpunkt seiner außenpolitischen Konzeption war das freundschaftliche Verhältnis zur Sowjetunion, das er zur Wiederherstellung der deutschen Ostgrenze für unabdingbar hielt. Allerdings dachte er dabei nicht, wie er einmal dem Zentrumsabgeordneten Franz v. Papen schrieb, an eine neue Teilung Polens ${ }^{14}$, ohne freilich dartun zu können, wie das bei einer gemeinsamen - politischen oder gar militäri-

12 In seinen Memoiren sagt er: „Für den deutschen Außenminister war der Aufenthalt in Genf eine Qual." Curtius, Sechs Jahre Minister, S. 167.

13 ADAP, Serie B, Bd. I, Nr. 26.

14 Bülow an Papen, 18. 9. 1930; PA, R 29465. 
schen - deutsch-sowjetischen Aktion gegen Polen vermieden werden beziehungsweise wie ein im Osten und im Westen kräftig beschnittenes RestPolen ohne Zugang zur Ostsee lebensfähig sein sollte.

Indes paßte zu solcher Bescheidung, daß Bülow an sich nicht unbedingt einen völligen Umsturz der europäischen Nachkriegsordnung im Auge hatte. Der Gedanke an eine deutsche Führung der Revisionisten-Partei lag ihm fern. „Wir haben ... kein Interesse, uns mit zweitklassigen Mächten zusammenzutun“, sagte er; deshalb „keine zu weite Annäherung an Italien“, erst recht kein Beitritt zum „italienischen Club der Lahmen und Blinden (Griechenland, Bulgarien, Türkei und Ungarn)"15. Schon gar nicht verstieg er sich zur sozusagen weltpolitischen Ambition einer Kooperation mit Japan, wie sie bereits damals in manchen Köpfen herumspukte: Er könne sich davon nichts versprechen, „ja nicht einmal etwas darunter vorstellen“ 16 . Er war deutscher Revisionist - punktum! In diesem Geiste stand er auf dem Boden des Brüningschen Programms, neigte jedoch insofern auch seinem Minister $\mathrm{zu}$, als er das eine oder andere territoriale Problem für lösbar hielt, sofern man es nur geschickt anstellte. Bei alledem entsprach seiner Natur im Grunde bedächtiges Vorgehen, und dieser Hang sollte im Laufe seiner Amtszeit noch zunehmen. Sein Karrieresprung hätte sicherlich viel böses Blut gemacht, wären nicht sein Wesen, sein Charakter und seine Fähigkeiten von den Kollegen sehr geschätzt worden. Neidlos konstatierte Ernst v. Weizsäcker in einem Brief an seine Mutter: „Es ist aber geradezu ein Amtsplebiszit, daß er der richtige sei." 17

Außerhalb Deutschlands ist die Bildung des Kabinetts Brüning zunächst nicht als zusätzliches oder besonderes Gefahrenmoment gesehen worden. Zwar konnte niemand verkennen, daß ein Rechtsruck stattgefunden hatte. Auch waren gerade die neuen Regierungsmitglieder, allen voran der Reichskanzler, bis zum Zeitpunkt der Ratifizierung mit herber Kritik am YoungPlan hervorgetreten; Brüning hatte im Reichstag nicht verhehlt, daß er und das Zentrum die Reparationsvereinbarung nur deshalb fürs erste akzeptierten, weil mit ihr die Räumung des Rheinlands erkauft werde. Dann gab es noch ein etwas beunruhigendes Indiz. Seit Herbst 1929 war zwischen Frankreich und Deutschland zäh und bislang ergebnislos über eine vorzeitige Rückgliederung des Saargebiets verhandelt worden. Es ging dabei im Kern um das Problem, wie auch nach dem politischen Anschluß des Saargebiets an das Deutsche Reich in irgendeiner Form französisches Miteigentum an den seit Versailles für fünfzehn Jahre französisches Eigentum gewordenen Saargruben gesichert werden konnte, Miteigentum oder doch Mitspracherecht bei ihrer Verwaltung, und wie das künftige Zollregime aussehen

15 Bülow an Dirksen, 14. 6. 1932; PA, R 29518.

16 Ebenda.

17 Weizsäcker-Papiere, S. 407. 
sollte. Die Zähigkeit, mit der die Vertreter Frankreichs verhandelten, obwohl die fruchtlose Streiterei um oft künstlich geschaffene Detailfragen beide Seiten enervierte und immer wieder die Regelung der Reparationen zu gefährden drohte, erklärte sich aus einem bedeutenden wirtschaftlichen Interesse Frankreichs: Paris wollte den seit Jahrzehnten gegebenen und in der Tat schützenswerten Zusammenhang zwischen der Saar und Lothringen, einen Zusammenhang, der sowohl für Kohle und Erz wie für die produzierende Industrie bestand, gegen etwaige politische Gefährdungen abschirmen. Nun war gar nicht zu übersehen: Kaum hatte das Kabinett Brüning die Geschäfte aufgenommen, trat die deutsche Verhandlungsdelegation drängender und fordender auf, schlug sie schärfere Töne an ${ }^{18}$.

Auf der anderen Seite durfte man sich sagen, daß Politiker wie Brüning dem Young-Plan am Ende eben doch zugestimmt, ja an seiner Annahme durch den Reichstag maßgeblichen Anteil gehabt hatten. Und wenn nicht $\mathrm{zu}$ übersehen war, daß die neue Regierung weniger vom Reichstag als vom Reichspräsidenten abhing, so stand hier einer Alarmreaktion entgegen, daß der Feldmarschall v. Hindenburg mittlerweile in aller Welt geradezu als Garant der Stabilität der inneren Verhältnisse Deutschlands galt. Sogar als Garant der Kontinuität Stresemannscher Politik. Die französischen und britischen Diplomaten hatten ausführlich berichtet, daß Hindenburg von vielen alten Freunden und Kameraden wie auch von vielen Standesgenossen unter massivsten Druck gesetzt worden war, sich gegen den Young-Plan zu stellen; manche hatten ihm vorgehalten, mit der Billigung des Plans begehe er Landesverrat, und angekündigt, ihm in einem solchen Falle nie mehr die Hand zu geben ${ }^{19}$. Hatte der alte Marschall dem Druck nicht standgehalten? War er nicht öffentlich für die Annahme eingetreten? Die Saarfrage wiederum brauchte als politisches Problem nicht allzu ernstgenommen zu werden. Schließlich stand der späteste Termin für die Rückkehr des Saarlands in den Reichsverband fest, und da dieser Termin nur noch ein paar Jahre entfernt war, konnte erwartet werden, daß die Deutschen die französischen Unartigkeiten nicht als Anlaß zum Stop der deutsch-französischen Annäherung nehmen würden. Vor allem aber: Am 30. Juni 1930, lange vor der in Versailles festgelegten Zeit, hatte der letzte alliierte Soldat das besetzte Rheinland zu verlassen. Mußte die deutsch-französische Annäherung davon nicht kräftige Impulse erhalten?

Indes gab das Kabinett Brüning doch bereits früh ein Signal, das die französische Regierung als Warnung auffassen konnte, daß von Berlin vielleicht nicht schon die Abkehr von der Politik Stresemanns, gewiß aber eine kräftige Modifizierung dieser Politik zu erwarten sei. Seit Herbst 1929 standen die

18 Hierzu die das Verlassen des Stresemann-Kurses gültig analysierende Darstellung von Knipping, Das Ende der Locarno- ̈̈ra, S. $124 \mathrm{ff}, 148 \mathrm{ff}$.

19 So Rumbold an Henderson, 22. 2. 1930; DBFP, Series Ia, Vol. VII, Nr. 250. 
Grundgedanken der Konzeption fest, die Briand für eine europäische Union entworfen hatte, und sie sind naturgemäß lebhaft diskutiert worden, noch ehe das offizielle Memorandum des französischen Außenministers am 17. Mai 1930 in den europäischen Hauptstädten überreicht wurde 20 . Reichsaußenminister Curtius traf zwei Tage vorher, als er sich anläßlich der 59. Tagung des Völkerbundsrats in Genf aufhielt, mit Briand zusammen und glaubte bereits diese Gelegenheit wahrnehmen zu müssen, dem Pariser Kollegen mitzuteilen, daß Deutschland durch nichts und niemand sein besonderes Verhältnis zu Rußland stören lassen werde ${ }^{21}$. Angesichts der revisionspolitischen - speziell antipolnischen - Zweckbestimmung der deutsch-sowjetischen Verbindung hatte der deutsche Außenminister damit unmißverständlich gesagt, daß das Deutsche Reich seine revisionpolitischen Ziele und seine revisionspolitische Bewegungsfreiheit nicht auf irgendeinem europäischen Altar opfern werde und daher Briands Europaplan, dem ja nur der Wunsch nach Sicherung des Status quo zugrunde liege, nicht annehmen könne.

Weder die Reichsregierung noch der Reichskanzler hatten Curtius zu dieser immerhin grundsätzlichen Erklärung offiziell ermächtigt. In den folgenden Wochen und Monaten stellte sich jedoch heraus, daß eine solche Ermächtigung überflüssig war. Curtius hatte mit Recht annehmen dürfen, die Meinung des Gesamtkabinetts wiederzugeben und in dessen Namen zu sprechen. Eine 26. Mai datierte Denkschrift des Auswärtigen Amts, die am 31. Mai der Reichskanzlei zuging, besagte unzweideutig, „die politische Diskussion über eine union fédérale européenne im Briandschen Sinne“ könne "gar nicht unmißverständlich genug abgelehnt werden“, und zwar aus Gründen der Revisionspolitik: „Wenn der Zeitpunkt der Revision vielleicht jetzt nicht gegeben ist, so können wir doch nicht auf die Möglichkeit einer solchen verzichten. Und wir würden darauf verzichten, wenn wir auf Briands Pläne einer, vertraglich festgelegten Solidarität' eingehen würden."22 Am 24. Juni folgte Treviranus, Reichsminister für die besetzten Gebiete, mit einer Aufzeichnung, in der es in gleichem Sinne hieß: „Der Angriff des Europaplans von Briand auf die Grundlagen der bisherigen außenpolitischen Aktionen Deutschlands ist um so gefährlicher, als er ... in den Zielen keinerlei Annäherung herbeiführt. In dieser Richtung handelt es sich insbesondere um die Stellungnahme des Plans zu der Frage der Revision der Friedensverträge... Die überwältigende Mehrheit der europäischen öffentlichen Meinung ... hat den Plan als eine Stabilisierung des durch die Friedensverträge geschaffenen Status Europas erkannt." Im Grunde wolle Briand Deutschland mit dem Europaplan lediglich in ein Ost-Locarno locken ${ }^{23}$. Und als das Kabinett am 8. Juli den vom Auswärtigen Amt formulierten

20 Knipping, Das Ende der Locarno-Ära, S. $155 \mathrm{ff}$.

21 Aufzeichnung Curtius, 15. 5. 1930; PA, R 27977.

22 AdRK, Die Kabinette Brüning, Bd. 1, Nr. 40.

23 AdRK, Die Kabinette Brüning, Bd. 1, Nr. 55. 
Entwurf der deutschen Antwortnote auf Briands Memorandum erörterte, sagte Reichskanzler Brüning, der Entwurf sei „vielleicht etwas zu vorsichtig gehalten“. Der Absicht Briands, „die jetzigen europäischen Zustände zu stabilisieren, müsse Deutschland eine Antwort geben, die als grundsätzliche Festlegung seiner Politik von geschichtlichem Wert sein könne. In deutlichen, wenn auch vorsichtig abgewogenen Worten müsse Deutschland gegenüber den französischen Aspirationen klare Grenzen aufzeigen. Seine Voraussetzungen für eine dauerhafte und gerechte Ordnung Europas, in dem Deutschland seinen ausreichenden natürlichen Lebensraum haben müsse, seien klarzulegen. ${ }^{24}$ Das waren große Worte, und die Verwendung eines Begriffs wie „Lebensraum“ könnte sogar dazu verleiten, eine Verwandtschaft zur Vorstellungswelt Hitlers und der Nationalsozialisten anzunehmen. Das wäre freilich verfehlt. Aber die Entschlossenheit, an der Revisionspolitik, gerade auch an der territorialen Revisionspolitik, festzuhalten, war in der Tat klar ausgesprochen und hat die Kernaussage der deutschen Antwortnote, die am 15. Juli der französischen Regierung übermittelt wurde, bestimmt. Überaus lang und recht verklausuliert, brachte die Note deutsche Ablehnung zum Ausdruck, nicht anders als der Reichsaußenminister am 15. Mai im Gespräch mit Briand. Curtius sprach von einem Begräbnis erster Klasse ${ }^{25}$.

Nun begegnete Briands Vorschlag in praktisch allen europäischen Staaten negativen Reaktionen, bestenfalls kühler Zurückhaltung. Der freundliche Ton, den die Regierungen in ihren Antworten auf Briands Memorandum anschlugen, konnte die Ablehnung nicht kaschieren; lediglich der Autor las zeitweilig in die im französischen Außenministerium einlaufenden Noten mehr Zustimmung hinein als gerechtfertigt. Die Zeit war selbst für bescheidensten freiwilligen Verzicht auf Souveränitätsrechte noch nicht reif. Aber für die Ruhe in Europa machte es naturgemäß einen grundlegenden Unterschied, ob ein Staat sich abwehrend verhielt, weil er seine Souveränität nicht antasten lassen wollte, oder ob ein Staat sich entzog, weil er sich mit dem Status quo auf dem europäischen Kontinent in Unfrieden befand. Italien deutete dieses Motiv an ${ }^{26}$, Ungarn sprach es offen aus ${ }^{27}$, und Deutschland, die in dieser Frage wichtigste europäische Macht, hatte zu erkennen gegeben, daß die Regierung Brüning gar nicht daran dachte, die ja seit dem Abschluß des Versailler Vertrags von nahezu allen politischen Gruppierungen im Reich pausenlos wiederholte Kampfansage an den Status quo zurückzunehmen. Die Frage, ob Stresemann seinen anfänglichen Enthusiasmus behalten und sich auf Briands Plan eingelassen hätte, ist schwer zu beantworten. Zwei Feststellungen dürfen indes gewagt werden. Wäre Stresemann nach

${ }^{24}$ AdRK, Die Kabinette Brüning, Bd. 1, Nr. 68.

25 Ebenda.

26 Schulthess', 1930, S. $473 \mathrm{f}$.

27 Ebenda, S. 477. 
genauerer Prüfung nicht bereit gewesen, sich mit den Ideen des französischen Außenministers anzufreunden, hätte er gleichwohl glaubhaft größtes Verständnis bekundet und bei seiner Absage französische Empfindlichkeiten so weit wie irgend möglich geschont. Viel wichtiger ist jedoch: Wäre er persönlich willens gewesen, einen weiteren Schritt von Annäherung zu Verständigung zu tun, Briands Europapläne zu akzeptieren und damit einer deutschen Anerkennung des Status quo ein Stück näher zu rücken, so hätte er das im Sommer 1930 nicht mehr durchzusetzen vermocht. Auch er nicht.

In Deutschland schäumte nämlich, kaum hatte sich die letzte französische Kompanie aus dem Rheinland nach Frankreich zurückgezogen, eine nicht mehr beherrschbare Welle des Nationalismus auf. Sie verursachte erstens eine schwere Krise der deutsch-französischen Beziehungen und ist zweitens auch in ihrer Bedeutung für die weitere Entwicklung der deutschen Außenpolitik kaum zu überschätzen ${ }^{28}$. Das - noch durchaus trügerische - Gefühl, endlich aller Fesseln ledig zu sein und sich auf internationalem Felde wieder frei bewegen zu können, produzierte nicht nur rhetorischen Nationalismus. Abgesehen davon, daß die nun nicht mehr geschützten Rheinländer, die als Separatisten oder sonst als Kollaborateure der französischen Besatzungsmacht galten, in vielen Fällen schwersten und übelsten Mißhandlungen ausgesetzt waren ${ }^{29}$, begannen nun, bildlich gesprochen, allenthalben im Deutschen Reich Banner zu wehen, die gerade mit den territorialen Forderungen des deutschen Revisionismus bestickt worden waren, und bei jeder Forderung fand sich der zusätzliche Anspruch: Erfüllung sofort! Organisationen wie der "Stahlhelm“, von der Deutschnationalen Partei und den Nationalsozialisten ganz zu schweigen, schlugen Töne an, die wie das Geklirr von Schwertern klangen, und auf Kundgebungen des "Stahlhelm" verlangten Führer wie der stellvertretende Bundesvorsitzende, Theodor Duesterberg, nicht allein die alsbaldige Rückkehr von Westpreußen und Ostoberschlesien, sondern ebenso von Eupen-Malmedy in Belgien und Elsaß-Lothringen in Frankreich ${ }^{30}$. In einem solchen Klima war an einen Ausbau der Locarno-Politik vorerst nicht mehr zu denken.

${ }^{28}$ Hierzu Knipping, Das Ende der Locarno-Ära, S. 143 ff. Der britische Botschafter schrieb dazu: „Der Schneeball der ,Revision' rollt die Abhänge der Wahllandschaft hinab und nimmt, während er rollt, an Tempo und Umfang zu. Man kann in der Tat sagen, daß die erste Wahlkampagne, die in Deutschland ohne den Schatten der Rheinlandbesetzung stattfindet, alles zum Vorschein bringt ..., auf das Deutschland auf dem Felde der Außenpolitik hofft und um das es sich bemühen wird." DBFP, Second Series, Vol. I, Nr. 318.

29 Aufzeichnung Curtius nach Gespräch mit dem französischen Botschafter, 7. 7. 1930; PA, R 27977.

30 Hoesch berichtete am 10.7. 1930 aus Paris, in Frankreich glaube man, „daß durch ganz Deutschland ... zur Zeit eine antifranzösische Welle" gehe; ernstzunehmende Franzosen schrieben der Botschaft, daß sie „sich wegen des Schicksals ihrer in Deutschland befindlichen Angehörigen beunruhigen“ oder daß "sie es nicht mehr wagten, ihre Sommerferien in Deutschland zu verbringen“; PA, R 28250 k. Zu Duesterberg Rieth an AA, 10. 10. 1930; PA, R 70024 . 
Der Ausbruch revisionistischer Stimmung war im übrigen nicht auf die nationalistische Rechte oder auf Politiker und Agitatoren ohne amtliche Verantwortung beschränkt. In den zahllosen Reden, in denen der Befreiung des Rheinlands gedacht wurde, ist auch das amtliche und offiziöse Deutschland nicht nur - was verständlich gewesen wäre - in nationales Pathos und nationalen Überschwang verfallen. In doppelter Weise wurden ominöse politische Zeichen gegeben. So kam in all den Feierstunden und Grußadressen Frankreich nur insofern vor, als vom Abzug der „fremden Besatzungstruppen“ und vom endlichen Verschwinden der „letzten Hoheitszeichen fremder Macht" gesprochen wurde. Die stets ausgedrückte Dankbarkeit der Nation galt einzig und allein der rheinischen Bevölkerung, die ihren Leidensweg unter Fremdherrschaft so tapfer und mit so vielen Opfern gegangen sei. Niemand hatte ein Wort des Dankes für den Staat übrig, der immerhin auf strikte deutsche Vertragserfüllung verzichtet, die Okkupation des Rheinlands vorzeitig beendet und die Befreiungsfeiern erst ermöglicht hatte. Und da Frankreich unerwähnt blieb, mußte natürlich auch die Hoffnung unausgesprochen bleiben, daß mit der Räumung des Rheinlands eine Phase noch intensiverer deutsch-französischer Zusammenarbeit beginnen werde. Das zweite politisch relevante Signal bestand darin, daß die enthusiastischen Sätze zum Ende der Besatzungsherrschaft sogleich und ohne weiteres mit der Forderung nach Erfüllung der nächsten revisionistischen Ansprüche verbunden wurden, und zwar so häufig und so selbstverständlich, daß die Anmeldung der zusätzlichen Ansprüche die Gestalt einer regelrechten Kampagne annahm.

Den Anfang machte ausgerechnet der sozialdemokratische Präsident des Reichstags, Paul Löbe, der am 30. Juni im Parlament seine Ansprache zur Räumung des Rheinlands offenbar ohne Bedenken mit der Bemerkung verknüpfte, daß noch nicht alle Wunden geheilt seien, die der Krieg gerissen habe: „Ich brauche nur an das Saarland zu erinnern." 31 Am folgenden Tag erließen Reichspräsident und Reichsregierung einen gemeinsamen Aufruf, in dem es hieß: „Noch harren unsere Brüder im Saargebiet der Rückkehr zum Mutterland. Wir grüßen heute deutsches Land und deutsches Volk an der Saar aus tiefstem Herzen und mit dem Gelöbnis, alles daran zu setzen, daß auch ihre Wiedervereinigung mit uns bald Wirklichkeit wird. "Der Aufruf schloß: „Einig wollen wir sein in dem Schwur: Deutschland, Deutschland über alles!“ An die Saarbevölkerung richtete Reichspräsident v. Hindenburg sogar ein eigenes Telegramm ${ }^{32}$. Nachdem der Feldmarschall erfahren hatte, daß die preußische Regierung nicht daran denke, das für die Rheinlande noch bestehende Verbot des "Stahlhelm" aufzuheben, sagte er am 15. Juli - in einem Schreiben an Ministerpräsident Otto Braun - seine 
bereits festgelegte Teilnahme an den Befreiungsfeiern in Koblenz, Trier, Aachen und Wiesbaden $\mathrm{ab}^{33}$. Um einen höchst unwillkommenen Skandal $\mathrm{zu}$ vermeiden, hob der preußische Innenminister das Verbot schon am folgenden Tag tatsächlich auf, was dem „Stahlhelm“ die Gelegenheit verschaffte, sich im Rheinland selbst zur Räumung der Besatzungszonen laut und mit einem revisionistischen Gesamt- und Sofortprogramm zu äußern, und was Hindenburg in die Lage versetzte, in seinen Reden auf den Befreiungsfeiern, die durch seine Gegenwart besonderes Gewicht gewannen, trauernd und fordernd zu erwähnen, daß für das Rheinland noch Entmilitarisierungsbestimmungen in $\mathrm{Kraft}$ seien ${ }^{34}$. Mit seinem wuchtigen Eintreten für eine radikalrevisionistische - und insbesondere frankophobe - Organisation und mit seiner eigenen Wendung gegen Locarno zeigte der oberste und jetzt mit zusätzlicher Macht ausgestattete ehrwürdige Repräsentant des Deutschen Reiches, daß der Glaube, gerade er verbürge die Fortsetzung Stresemannscher Politik, eine Illusion gewesen war.

In ganz Europa, vor allem aber in Frankreich, beobachteten Diplomaten, Politiker und Öffentlichkeit mit wachsender Konsternation, daß sich die deutschen Reaktionen auf die Räumung des Rheinlands zu einer einzigen Absage an die mit Locarno eingeleitete Politik summierten. Die Berliner Botschafter vieler europäischer Staaten erschienen im Auswärtigen Amt und suchten bei Curtius oder Bülow die beruhigende Versicherung zu bekommen, daß der Anschein trüge und sie nicht gerade das Begräbnis der Politik Stresemanns erlebten, während sich die Vertreter revisionistischer Länder im Gegenteil die Gewißheit verschaffen wollten, daß der Anschein eben nicht trog. In Paris wiederum mußten sich Hoesch und seine Mitarbeiter einen vielstimmigen Klagechor französischer Politiker anhören, die allesamt Deutschland und die Deutschen gröbster Undankbarkeit beschuldigten. Wenn Hoesch dies nach Berlin berichtete ${ }^{35}$ - oder wenn sich dort der französische Botschafter ähnlich äußerte ${ }^{36}$-, so haben die deutschen Empfänger nie verstanden oder verstehen wollen, daß natürlich nicht Dankbarkeit im Alltagssinne, sondern Dankbarkeit im politischen Sinne eingefordert wurde, also eine Honorierung des vorzeitigen Abzugs der französischen Truppen durch deutsche Erklärungen, namentlich durch Erklärungen von Mitgliedern der Reichsregierung, daß Deutschland jetzt, nach der Räumung des Rheinlands, die deutsch-französische Annäherung erst recht fortsetzen wolle. Hoesch meldete ferner - und das war noch ernster-, daß man sich gerade auch in den an sich annäherungswilligen Kreisen der französischen Mitte und Linken zu fragen beginne, ob Frankreich mit der Rheinlandräumung nicht eine „Dummheit“ gemacht habe, und daß Briands poli-

33 Ebenda, S. 168.

34 Ebenda, 1930, S. 173 f.; Hoesch an AA, 1. 8. 1930; PA, R 70502.

35 So am 4. 9. 1930, Hoesch an AA; PA, R 70502.

36 Etwa am 31. 7. 1930, Aufzeichnung AA; PA, R 70502. 
tisches Prestige nicht unbeträchtlich beschädigt worden sei ${ }^{37}$. Beides war auch deshalb von Bedeutung, weil es zu dem Schluß nötigte, daß sich die deutsche Reaktion auf das Ende der Okkupation zu einem Hindernis für weitere Fortschritte deutscher Revisionspolitik auszuwachsen drohte.

Hoesch machte immer wieder Versuche, in Berlin Verständnis für die französische Enttäuschung und Verbitterung zu wecken. So schrieb er am 25. Juli 1930: „Was bedeutet Deutschland in London, Rom und Washington? Eine Großmacht unter mehreren Großmächten neben vielen anderen Faktoren und Interessen. Was bedeutet es in Frankreich? Das Zentrum der französischen Politik, gegenüber dem alles andere erst in zweite Linie tritt. Politisch mit einander um die Verständigung ringend, psychologisch ununterbrochen in empfindlicher Weise auf einander reagierend, wissenschaftlich und kulturell sich durchdringend und befruchtend, wirtschaftlich einander ergänzend und sich zustrebend, so werden Deutschland und Frankreich ihren Weg in der Welt weitergehen müssen, und Sache der Staatskunst wird es sein, diesen Entwicklungsprozeß zum guten Ende zu führen.“38

Mit solchen Worten hatte Hoesch freilich nur seine eigene Frankreichpolitik skizziert, nicht das frankreichpolitische Programm des Landes, das er in Paris vertrat. Tatsächlich sollte sich das politische Klima in Deutschland binnen weniger Wochen noch drastisch verschlechtern. Mitte Juli 1930 lehnten SPD, KPD, DNVP und NSDAP Reichskanzler Brünings Programm zur Haushaltsdeckung erwartungsgemäß ab. Auch die danach fällige Notverordnung wurde von einer Reichstagsmehrheit verworfen. Daraufhin löste Brüning mit Zustimmung Hindenburgs den Reichstag auf, die Neuwahl wurde auf den 14 . September festgelegt. Der sofort einsetzende Wahlkampf hat die im Lande ohnehin herrschende politische Erregung zur Siedehitze gesteigert. Auch bei den Parteien der Mitte und der demokratischen Linken kam es nun zu Ausbrüchen eines blindwütenden Nationalismus, zumal sie mit der chauvinistischen Propaganda der Deutschnationalen und der Nationalsozialisten konkurrieren zu müssen glaubten. Gewiß trug auch die Verschlechterung der Wirtschaftslage zur Verschlechterung der politischen Stimmung bei. Jedoch hatten erst wenige das Gefühl oder die Einsicht, schon tief in einer epochalen Krise zu stehen. Zwar litt der Export unter der in vielen Teilen der Welt bereits um sich greifenden Kaufkraftschwäche, und die Landwirtschaft steckte durch Preisverfall und die Anfänge der Brüningschen Deflationspolitik in großen Schwierigkeiten ${ }^{39}$. Aber noch flossen die Gelder ausländischer Anleger; auch amerikanische Investoren hatten, dem New Yorker Börsenkrach vom Oktober 1929 zum Trotz, noch keinen Anlaß gesehen, Kredite aus Deutschland abzuziehen. Und die Zahl

37 Hoesch an AA, 25. 7. 1930; PA, R 70502.

38 Ebenda.

39 Dazu vor allem James, The German Slump, S. $190 \mathrm{ff} ., 246 \mathrm{ff}$. 
der Arbeitslosen, wenngleich wesentlich höher als 1929 oder gar 1928, sprengte noch nicht - wie kurze Zeit später - alle gewohnten Maßstäbe; im übrigen kam die Arbeitslosigkeit in jenen Monaten noch mehr dem Linksals dem Rechtsradikalismus zugute.

$\mathrm{Daß}$ die nationalistischen Töne während dieses Wahlkampfes schriller klangen, die revisionistischen Forderungen an die Außenwelt ungenierter und heftiger gestellt wurden, kam tatsächlich in erster Linie aus einem $\mathrm{Ge}$ fühl, das der Abzug aller fremder Besatzungstruppen aufkommen ließ, aus dem Gefühl, endlich frei und ungestraft vom Aufstand gegen Versailles wenigstens reden zu dürfen. Damals war das klarer als im Rückblick. Ebenso lag auf der Hand, daß die Welle des Nationalismus vornehmlich der NSDAP Adolf Hitlers Stimmen zutreiben werde, die sich seit 1928/29 ohnehin im Vormarsch befand, wie lokale und regionale Wahlen gezeigt hatten, und die gerade eben von den Deutschnationalen als Partner beim Volksbegehren gegen den Young-Plan akzeptiert und damit auch für ehrbares Bürgertum „hoffähig“ und wählbar gemacht worden war. Briand sagte zu Hoesch, die Frage nach dem Ausgang der deutschen Wahlen stelle derzeit die „Hauptsorge“ der französischen Regierung dar. Ob wohl ein vollständiger Umschwung der politischen Situation in Deutschland bevorstehe? Und es machte seinem Urteil alle Ehre, daß er, wie der Botschafter schrieb, „einen Horror bei dem Gedanken“ empfand, die beiden Gefahren, die kommunistische und die nationalsozialistische, könnten sich zu einer Gefahr verbinden ${ }^{40}$. Hoesch suchte zu beruhigen und erklärte einen vollständigen Umschwung in Deutschland für „schlechthin ausgeschlossen“; vielleicht würden „hundert rein negative Abgeordnete“ (KPD und NSDAP) im nächsten Reichstag sitzen ${ }^{41}$.

Als diese Unterhaltung zwischen Briand und Hoesch stattfand, am 4. August 1930, waren die für französische Ohren erschreckendsten Reden deutscher Politiker noch gar nicht gehalten worden. Am 10. August veranstalteten die Ostverbände anläßlich der zehnten Wiederkehr des Abstimmungstags in West- und Ostpreußen eine Kundgebung vor dem Reichstag. Schmuck der Kundgebung war eine Rede des Reichsministers für die besetzten Gebiete, Gottfried Treviranus. Weizsäcker, selber aus der kaiserlichen Marine hervorgegangen, schrieb einmal in einem Brief an seine Mutter: „Treviranus ist ehemaliger Seeoffizier, aber nicht beste Sorte."42 Als er an jenem 10. August sprach, scheint sich Treviranus jedenfalls nicht im Zivil eines Regierungsmitglieds, sondern in der jahrelang getragenen Uniform eines Torpedobootfahrers gewähnt zu haben. Kaum hatte er das Aufatmen des ganzen deutschen Volkes konstatiert, weil „die bittere Zeit des Zwanges,

40 Hoesch an AA, 4. 8. 1930; R 70502.

41 Ebenda.

42 Weizsäcker-Papiere, S. 401. 
der Anblick fremder Uniformen vorbei ist“, kaum hatte er „in Wehmut, aber auch in unbeugsamer Hoffnung die Brüder an der Saar wie die Eifelwacht in Eupen und Malmedy" gegrüßt, da wandte er sich mit Worten gegen Polen, als wolle er den baldigen Einmarsch der Reichswehr in Westpreußen ankündigen: „Nun fordert der Osten Einheit und Einsatz des ganzen deutschen Volkes. Wir gedenken in der Tiefe unserer Seele des zerschnittenen Weichsellandes, der ungeheilten Wunde in der Ostflanke, diesem verkümmerten Lungenflügel des Reichs... Ostdeutschlands Blutstokkung bleibt eine europäische Sorge und Gefahr... Weg mit dem Gerede von der Katastrophe, her mit dem Mut, alle Nöte zu bannen." 43

Nun konnte man solche Sätze jeden Tag in der rechten Presse lesen und in Versammlungen der DNVP oder NSDAP hören. Daß aber ein Mitglied der amtierenden Reichsregierung derartige Töne anschlug, war eine europäische Sensation. Der Schrecken in Deutschlands Nachbarstaaten nahm noch zu, als einen Tag nach dem Auftritt von Treviranus ein weiterer Angehöriger des Kabinetts Brüning das offizielle Startsignal zum Kampf gegen Locarno zu geben schien. Ausgerechnet auf der Verfassungsfeier der Reichsregierung sagte Reichsinnenminister Wirth, vom linken Flügel des Zentrums kommend, jedoch leidenschaftlicher Nationalist: „In unserer Freude über die Befreiung der rheinischen Lande übersehen wir aber nicht, daß Räumung nicht restlose Freiheit bedeutet. Das Land am Rhein ist auch fernerhin noch ein Land mindern Rechts. Wahre Freiheit gewinnen wir erst dann, wenn der Weg vom mindern Recht zum gleichen Recht zu Ende gegangen ist. "44

In den folgenden Tagen und Wochen registrierte man in ganz Europa mit größter Beunruhigung, daß weder der Reichskanzler noch der Reichsaußenminister einschränkende Worte zu den Ansprachen ihrer stürmischen Kollegen für nötig hielten, also die Meinung der Redner anscheinend teilten. Der Anschein entsprach auch der Realität. Wohl gab es interne Kritik. In der Sache machte aber nur der deutsche Gesandte in Warschau, Ulrich Rauscher, Front gegen Treviranus. Von seinem Urlaubsdomizil in Nonnenhorn am Bodensee donnerte er: Tatsächlich „aber ist die Rede eine offene Kampfansage gegen Polen und wird, als Auslassung eines aktiven Reichsministers, von Warschau als vollgültiger Beweis des Bedrohtseins ... verwertet werden" 45 . Staatssekretär v. Bülow mißbilligte immerhin Form und Zeitpunkt. In einer Unterhaltung mit dem polnischen Gesandten gab er zu, daß Polen Anlaß habe, sich über Treviranus zu erregen ${ }^{46}$, und an Rauscher schrieb er, die akute Belastung, die Treviranus' Äußerungen bescherten, würde er gerne in Kauf nehmen, wenn „nicht zu befürchten wäre, daß sie auch auf

43 Schulthess', 1930, S. 188 f.

44 Ebenda, S. 191.

45 Rauscher an Bülow, 13. 8. 1930; PA, R $28320 \mathrm{k}$.

46 Aufzeichnung Bülow, 16. 10. 1930; PA, R 29449. 
weite Sicht nur ungünstige Wirkungen haben werden und uns vielleicht wieder um Jahre zurückwerfen werden" 47 .

Außenminister Curtius hingegen protestierte lediglich - wenn auch mit Schärfe - dagegen, daß Treviranus sich mit seinen - noch dazu programmatischen - Sätzen zur Außenpolitik Kompetenzen angemaßt habe, die neben dem Reichskanzler allein ihm, dem Reichsaußenminister Julius Curtius, zustünden ${ }^{48}$. Was den Inhalt betraf, stimmte er jedoch mit seinem Kollegen überein, jedenfalls in der Polenfrage. Am 20. August, zehn Tage nach der Rede von Treviranus, sagte er in einer Kabinettssitzung, schon seit den Verhandlungen um den Young-Plan stehe er mit Rußland in Fühlung, um die Rückgewinnung des Korridors vorzubereiten ${ }^{49}$, und wenn er auch tadelte, daß Treviranus, von der Kompetenzüberschreitung abgesehen, die Franzosen zu früh und zu stark alarmiere, so gab er einige Monate später, als der Reichskanzler vor einer Reise nach Beuthen stand, um dort am zehnten Jahrestag der Abstimmung in Schlesien teilzunehmen, Brüning den Rat, eindringlich von der „blutenden Grenze“ zu sprechen; das werde seinen Eindruck auf das Ausland nicht verfehlen ${ }^{50}$.

Der Reichskanzler sah überhaupt keinen Grund zur Rüge, wenn er natürlich auch bemüht war, seinen gekränkten Außenminister zu beruhigen. Der danach gänzlich unbußfertige Treviranus übertraf sich noch selbst, als er am 26. August in Königsberg eine Rede hielt, in der er abermals einen Ausflug auf das Feld der Außenpolitik unternahm. Revision sei nötig, so sagte er, indes könne der „Zeitpunkt für eine solche Aktion doch erst dann bestimmt werden, wenn die innere Stärke unseres Volkes uns die Gewißheit gibt, daß wir Atemkräfte genug haben, um einen solchen Anspruch durchzuhalten" 51 . Und obwohl ein solcher Spruch innerhalb wie außerhalb Deutschlands naturgemäß als Ankündigung verstanden wurde, daß das Deutsche Reich, sobald es wieder über eine schlagkräftige Armee verfüge, über Polen herfallen werde, und obwohl die Pariser Botschaft wissen ließ, wie sehr ihre französischen Gesprächspartner nach einem klärenden Wort des Kanzlers lechzten ${ }^{52}$, fiel es Brüning nicht ein, sich von Treviranus zu distanzieren. In Trier sagte er am 31. August in einer Wahlrede lediglich, in der deutschen Außenpolitik sei es nicht damit getan, dieses oder jenes Endziel programmatisch aufzustellen. Die Endziele ergäben sich aus der gesamten Lage

47 Bülow an Rauscher, 20. 8. 1930; PA, R 29513.

48 So in einem Telegramm an Treviranus, 1.9. 1930; PA, R 29505. Seine Kritik im Kabinett, AdRK, Die Kabinette Brüning, Bd. 1, Nr. 110.

49 AdRK, Die Kabinette Brüning, Bd. 1, Nr. 104.

50 AdRK, Die Kabinette Brüning, Bd. 2, Nr. 256.

51 Über die Realstion Briands berichtete Gesandtschaftsrat Hans Riesser aus Paris am 20.8. 1930; PA, R $28251 \mathrm{k}$.

52 So Riesser am 20. 8. 1930 nach einem Gespräch mit André Lefebvre de Laboulaye, dem stellvertretenden Leiter der Politischen und Handelsabteilung im französischen Außenministerium; PA, R 70502. 
Deutschlands von selbst, und über sie könne und solle in Deutschland kein Streit $\operatorname{sein}^{53}$. Das konnte eher als Bestätigung der Reden seines Ministers verstanden werden, im Grunde auch seine anschließende Bemerkung, er und der Außenminister seien verfassungsmäßig für die Führung der Außenpolitik allein verantwortlich, und sie beide böten doch die Gewähr dafür, daß das Schicksal des deutschen Volkes nicht in irgendwelche Abenteuer verstrickt werde, was keinem verantwortlichen deutschen Staatsmann in den Sinn kommen könne. Nach Treviranus' erster Ansprache hatte der britische Botschafter an Außenminister Arthur Henderson geschrieben, nach seiner Meinung ergebe sich die Bedeutung des Vorfalls mehr aus dem, was Treviranus zu sagen unterlassen habe, nämlich daß Deutschland die Revision seiner Ostgrenze nur mit Hilfe des Artikels 19 der Völkerbundssatzung, also nur mit friedlichen Mitteln, anstreben werde. Treviranus sei ein junger und offenbar eigenwilliger ehemaliger Marineoffizier, doch zeige sich in seiner Haltung eine derzeit in Deutschland erkennbare Tendenz, zu weit und $\mathrm{zu}$ schnell $\mathrm{zu}$ gehen ${ }^{54}$. Brüning tat nichts, um solche Eindrücke abzuschwächen, namentlich nichts zur Beruhigung Frankreichs.

So konstatierte Sir Horace Rumbold einige Tage später mit Fug und Recht, nachdem ihm ein „offensichtlich verlegener" Bülow versichert hatte, Treviranus habe seine Rede nicht mit dem Auswärtigen Amt abgesprochen und sich nicht im Namen der Regierung, sondern inoffiziell geäußert - „soweit die Rede eines verantwortlichen Ministers inoffiziell sein kann“: „Reden wie die des Herrn Treviranus sind nicht geeignet ..., die Dinge im deutschen Sinne $\mathrm{zu}$ bessern. Sie können nur Unruhe und Irritation unter Deutschlands Nachbarn schaffen. "55 In der Tat provozierte Treviranus eine ungeheure Erregung, vor allem in Polen und Frankreich, aber auch in Staaten wie Belgien und der Tschechoslowakei. In Paris hatten Poincaré und Louis Barthou, der mehrmals Minister und auch Regierungschef gewesen war, schon auf die Reden Hindenburgs bei den Befreiungsfeiern heftig reagiert. Barthou hatte sogar geschrieben, der Reichspräsident habe „die bisher geheim gehaltenen Absichten der deutschen Regierung zu enthüllen begonnen" - damit war ein deutscher Angriff auf Locarno gemeint ${ }^{56}$. Poincaré hatte zur Kritik Hindenburgs und anderer deutscher Politiker an der Entmilitarisierung des Rheinlands bemerkt, diese Entmilitarisierung sei ein wesentlicher Teil der Vereinbarungen von Locarno, und es könne einfach nicht akzeptiert werden, daß eine derartige Verpflichtung mit „der Würde und der Souveränität" des Deutschen Reiches nicht vereinbar sei; schließlich habe sich Frankreich sechzig Jahre lang mit der Neutralisierung von Sa- 
voyen abgefunden ${ }^{57}$. Jetzt aber nahm er den Fehdehandschuh, den Treviranus allen Verteidigern des Status quo vor die Füße geworfen hatte, mit sichtlicher Freude auf und behauptete in einem Artikel, der sich ebenso gegen die französischen Anhänger einer Annäherung an Deutschland wie gegen die Deutschen und ihre Politik richtete, die deutsche „Mentalität" habe sich „seit den Tagen Treitschkes und Bernhardis nicht wesentlich geändert... Die Ausbildung des deutschen Heeres und der deutschen Jugend an den Universitäten wird im alten Geist fortgesetzt. " 58 Der Artikel gipfelte in dem unzweideutigen Satz: „Das Verlangen nach Revision bedeutet einen Kriegsruf."

So und so ähnlich rauschte es im gesamten französischen Blätterwald. In vielen Zeitungen war tatsächlich von „Kriegsgefahr“ die Rede. Ernster mußte genommen werden, daß Hoesch aus Paris meldete, auch Kabinettsmitglieder sprächen von einer offenkundigen „Umgestaltung der deutschen Politik“, hielten dafür, die Rheinlandräumung sei also wohl ein Fehler gewesen, und meinten, das Kabinett werde sich von Briand, dem großen Repräsentanten der französisch-deutschen Annäherung, trennen müssen ${ }^{59}$. Und in London entstand, wie Botschaftsrat Graf Albrecht Bernstorff berichtete, da und dort die Ansicht, die Zunahme von Kommunisten und $\mathrm{Na-}$ tionalsozialisten sei nicht so gefährlich „wie die jetzt betriebene allmähliche Unterhöhlung der Stresemann-Politik“60.

Dann kam der 14. September 1930, und das Ergebnis der Wahlen zum Reichstag jagte allen, die wie Hoesch in der Unterhaltung mit Briand nur ein noch ungefährliches Ansteigen der braunen und der roten Flut erwartet hatten, einen tiefen Schrecken ein. Die Nationalsozialisten vervielfachten ihren Stimmenanteil; sie allein entsandten nun 107 Abgeordnete in den Reichstag. Die Kommunisten verzeichneten ebenfalls einen großen Erfolg: zu den 54 Sitzen, die sie am 20. Mai 1928 erobert hatten, gewannen sie 23 hinzu und waren also jetzt mit 77 Abgeordneten vertreten.

Nun waren die Nationalsozialisten außerhalb Deutschlands noch eine nahezu unbekannte Größe. Zwar sind sie, da ihr Gewicht in Kommunen und Ländern schon seit 1928/29 zunahm, von den ausländischen Missionen in Deutschland aufmerksam beobachtet worden. Nach den Gemeindewahlen in Preußen, Sachsen und Hessen hatte Harold Nicolson am 29. November 1929 an das Foreign Office geschrieben, das „hervorstechende Merkmal dieser Wahlen ist der gänzlich unerwartete Triumph oder, richtiger gesagt, das Erscheinen der Nationalsozialisten“. Das seien "gefährliche Leute“: „rote Faschisten oder linke Chauvinisten“61. Einige Wochen später hat Sir

57 Ebenda.

58 Riesser an AA, 15. 8. 1930; PA, R 70502.

59 Hoesch an AA, 12. 8. 1930; PA, R $28251 \mathrm{k}$.

60 Albrecht Graf von Bernstorff an AA, 28. 8. 1930; PA, R 28305 k.

61 DBFP, Series Ia, Vol. VII, Nr. 87. 
Horace Rumbold die Erfolge der NSDAP mit den Sätzen kommentiert: „Der deutsche Charakter, so bewundernswert er in vieler Hinsicht ist, weist einen notorischen Mangel an politischer Vernunft auf... Neben den solideren Parteiorchestern haben sie [die Nationalsozialisten] die magnetische Attraktivität einer Jazzband."62

Abgesehen davon, daß solche Urteile noch recht ratlos klingen, erreichten sie natürlich nicht die Öffentlichkeit. Um so mehr Angst erweckten die lauten, groben und gewalttätigen Gefolgsleute eines ebenfalls noch völlig unbekannten Adolf Hitler. Man glaubte zu sehen, daß sie radikaler, zumindest aber unbesonnener seien als die Deutschnationalen, und so traute man ihnen alles zu: Putsch und Errichtung einer Diktatur oder auch Restauration der Hohenzollern, Aufrüstung und Krieg - war nicht die SA schon ein Heer, jünger und daher draufgängerischer als der "Stahlhelm“? -, sofort jedoch Einstellung der Reparationszahlungen und Liquidierung von Locarno. Außerdem berichteten die ausländischen Korrespondenten wie die ausländischen Diplomaten, welch radikalen und brutalen Antisemitismus die NSDAP vertrete und welche Angst daher das Wahlergebnis bei den Deutschen mosaischer Konfession und jüdischer Herkunft ausgelöst habe ${ }^{63}$.

Für die internationalen Beziehungen wirkte sich der nationalsozialistische Erfolg in dreierlei Hinsicht aus. Erstens erreichte in Frankreich die Furcht vor dem in mehr als vier Jahren nur mühsam und nur mit Hilfe starker Bundesgenossen niedergerungenen Nachbarn eine neue Dimension. Die Wahlen schienen den Beweis dafür geliefert zu haben, daß das seit Anfang Juli ständig gewachsene Mißtrauen nur allzu berechtigt war. Statt mit Dankbarkeit und belebter Versöhnungsbereitschaft reagierten die Deutschen auf stetes französisches Entgegenkommen offensichtlich mit fortschreitender Freisetzung eines rabiaten Chauvinismus und des Willens zur Revanche. Die Kriegsangst breitete sich weiter aus und bewegte die Gemüter noch stärker als zuvor. Zugleich nahm aber auch die Entschlossenheit zu, sich zu wehren und Deutschland an einem Revanchekrieg entweder mit politischen Mitteln oder durch die Wahrung eines ausreichenden Unterschieds in der einsetzbaren militärischen Kraft zu hindern. Im Oktober 1930 stand ein Kongreß der Radikalsozialisten ganz im Zeichen der Ansicht, das Anschwellen eines extremen Nationalismus in Deutschland sei eine unmittelbare Folge der Rheinlandräumung. Ein Redner nach dem anderen verlangte in Grenoble mit Ungestüm eine radikale Änderung der französischen Außenpolitik, und Angriffe auf Briand häuften sich ${ }^{64}$. Anfang November stellte der Abgeordnete Henri Franklin-Bouillon in der Kammer die gleiche

62 DBFP, Series Ia, Vol. VII, Nr. 142.

63 Rumbold an Henderson, DBFP, Second Series, Vol. I., Nr. 324.

64 Rieth an AA, 11. 10. 1930; PA, R 27977. 
Forderung und warnte vor jeder weiteren Konzession an Deutschland; das fand auf der gesamten Rechten und auch bei Teilen der Linken lebhaften Beifall: „Bei der Feststellung, daß Polens Grenzen auch Frankreichs Grenzen seien, erhob sich ein wahrer Beifallssturm bis weit in die Reihen der Linken hinein." 65 Auch deutsche Besucher Frankreichs berichteten an das Auswärtige Amt, das Gefühl der Verbundenheit mit Polen sei außerordentlich stark. Tatsächlich war das Bewußtsein sehr lebendig, mit Polen in einem Boot zu sitzen. So konnte man um diese Zeit im „Journal des Débats“ lesen: Nach Erfüllung aller deutscher Forderungen „befände man sich einem stärkeren Deutschland gegenüber als dem von 1914. Man müßte besonders naiv sein, wollte man sich einbilden, daß Deutschland, wenn es dieses Ergebnis hat, sich nicht in sehr aktiver Weise auch für seine Westgrenze interessieren würde."66

Noch waren Briand und seine Anhänger stark genug, um an der Macht zu bleiben, ihre Politik jedoch hatte einen schweren Stoß erhalten. Konnte sie fortgesetzt werden? Die deutschen Diplomaten in Frankreich, von denen die Reichsregierung getreulich über die Ausschläge der französischen Stimmung unterrichtet wurde, säumten nicht, ihren Hiobsbotschaften deutliche Hinweise anzuhängen, daß es der deutschen Regierung angesichts der prinzipiellen Annäherungsbereitschaft der meisten Franzosen im Grunde ein leichtes sei, durch freundliche Worte, Gesten und Handlungen Briand und Briandsche Politik zu stützen ${ }^{67}$. Manch anderer Beobachter beantwortete die Frage indes bereits verneinend. Im November 1930 schrieb Brigadegeneral A.C. Temperley, Leiter der Informationsabteilung im britischen Kriegsministerium, eine die Verhältnisse in Deutschland präzis analysierende Denkschrift, in der er, ausgehend von der Feststellung, daß elf Millionen Deutsche (4,5 Millionen Kommunisten - 6,5 Millionen Nationalsozialisten) für Gewalt, für die Ablehnung verfassungsmäßigen Regierens und gegen alle mit den Friedensverträgen verbundenen internationalen Abkommen gestimmt hatten, zu dem Schluß kam, Briand und seine Freunde seien desavouiert: „Die Politik der Annäherung und der Abrüstung ist, jedenfalls für den Augenblick, mausetot." 68

Als zweite Folge des Wahlresultats erlitt - zum ersten Mal wieder seit der Währungsreform von 1923/24 - der deutsche Kredit eine ernste Beschädigung. Die Zukunft Deutschlands schien plötzlich voller Gefahren zu sein, lag jedenfalls im ungewissen. Mit den Nationalsozialisten standen plötzlich

65 Hoesch an AA, 6. 11. 1930; PA, R 27977.

66 Zit. nach Berliner Tageblatt, 29. 12. 1930.

67 Hoesch machte z.B. am 13.11. 1930 darauf aufmerksam, daß Briand, als er sich am gleichen Tage in der Kammerdebatte „erneut in mutigen und überzeugten Worten zur Annäherungspolitik mit Deutschland" bekannte, stürmischen Beifall geerntet habe, abgesehen von den Kommunisten und der äußersten Rechten; PA, R 70503.

68 Dufour-Feronce an AA; PA, R 29512. 
Leute im Vorhof der Macht, denen man, setzten sie ihren Aufstieg fort, eine abenteuerliche Politik zutrauen mußte, jedenfalls die Einstellung der Reparationszahlungen, vielleicht sogar die Unterbindung aller Zahlungen an das Ausland. Schon jetzt war zu befürchten, daß Hitler und die NSDAP, immerhin nun zweitstärkste Partei nach der SPD, allein durch ihre Existenz und ihre Propaganda die amtierende Regierung unter Druck setzten und noch ein Stück weiter nach rechts trieben - zunächst im Hinblick auf den Young-Plan. Solche Ängste befielen zahlreiche ausländische Anleger, ob in New York, London oder Zürich. Kurzfristige Kredite wurden in Höhe von etlichen Milliarden Mark abgezogen ${ }^{69}$. Der so verletzliche finanzielle Kreislauf, von dem die deutsche Wirtschaft zu einem guten Teil lebte und der auf Grund der zunehmenden einheimischen Investitionsschwäche von Monat zu Monat wichtiger wurde, erhielt einen bösen Schock. Noch brach der Kreislauf nicht zusammen. Sowohl Reichsregierung und Reichsbank wie die Regierungen und die Zentralbanken der bedeutenderen Gläubigerstaaten wirkten der Panik energisch entgegen. Auch in Frankreich - französische Kreditgeber hatten rund 400 Millionen Franc abgezogen - sorgten Briand und die Bank von Frankreich für Beruhigung namentlich der Großbanken ${ }^{70}$. Aber großer Schaden war angerichtet, der die ohnehin kriselnde deutsche Wirtschaft hart traf und der aus eigener Kraft vorerst nicht behoben werden konnte.

So hat der Wahlerfolg der NS-Bewegung, partiell gewiß Resultat einer bereits ausgebrochenen Wirtschaftskrise, diese Krise jäh und drastisch verschärft. Aus dem finanziellen Vorgang ergab sich für den Moment jedoch vor allem eine Lehre: Wenn Deutschland und die Deutschen mit ihren Auslandsverpflichtungen, gerade auch mit dem Young-Plan, nicht behutsam umgingen, steuerten sie in eine regelrechte Katastrophe. Die Lage, die sich hier darbot, war nicht ohne Paradoxie. Drohte das Deutsche Reich mit der Verfechtung politisch und moralisch zumindest dubioser Revisionsansprüche, nämlich der territorrialen Forderungen, gleich ganz Europa in Brand zu stecken, weil sich dabei kriegerische Auseinandersetzungen womöglich nicht vermeiden ließen, so brachte ausgerechnet die Verfechtung des einen politisch, wirtschaftlich und moralisch durchaus vertretbaren Anspruchs, nämlich des Verlangens nach der Liquidierung einer unsinnig hohen und unmoralisch langfristigen Reparationslast, zuerst und vor allem die Selbstzerstörung.

Gleichwohl schickte sich die Reichsregierung an, alle bedenklichen Wege auf einmal einzuschlagen. Das lag in der Tat auch am dritten Effekt des Triumphs der NSDAP. Die Annahme, das Kabinett werde unter den Druck der NS-Bewegung geraten oder sich doch einem solchen Druck ausgesetzt

${ }^{69}$ Keese, Die volkswirtschaftlichen Gesamtgrößen.

70 Rieth an AA, 19. 9. 1930; PA, R 27977. Aufzeichnung Curtius, 24. 9. 1930; PA, R 27997. 
fühlen, bestätigte sich sofort. Einen Tag nach der Wahl teilte Bülow dem zur 60. Tagung des Völkerbundsrates in Genf weilenden Curtius mit, er solle in seiner Rede die Mitschuld des Auslands am Wahlergebnis betonen und deutlich machen, daß die deutsche Regierung zwar nach wie vor entschlossen sei, in Zusammenarbeit mit anderen Ländern am Wiederaufbau in Europa mitzuwirken, jedoch nur auf der Basis wirklicher Gleichberechtigung und Freiheit; das Wort „Verständigungspolitik“ müsse dabei vermieden werden. Dies sei die Meinung des Reichskanzlers, des Ministers Treviranus, der dem Zentrum angehörenden Minister und des Prälaten Ludwig Kaas, des Vorsitzenden der Zentrumspartei ${ }^{71}$. Kaas übte in revisionspolitischen Fragen ohnehin einen alles andere als bremsenden Einfluß auf Brüning aus. In jenen Monaten schrieb er ein Vorwort zu einem Werk über deutsche Außenpolitik, das der „Außenpolitiker“ der Zeitschrift „Germania“, Walter Hagemann, verfaßt hatte, und in diesem Vorwort sagte er, „der deutsche Samson wird sich nicht auf Lebenszeit an die Tretmühle von Versailles binden lassen“, und es könne die Zeit kommen, „wo die Samsontragödie sich im Politischen wiederholt und die Wächter des status quo unter den splitternden Balken ihres eigenen Hauses begraben werden “72.

Curtius befolgte die Berliner Instruktion und hielt eine Ansprache, in der weniger von deutsch-französischer Annäherung und mehr von der Vertretung deutscher „Lebensnotwendigkeiten“ die Rede war, in der ferner der Begriff „Verständigungspolitik“ nicht nur vermieden, sondern durch den Begriff „evolutionäre Politik“ ersetzt wurde ${ }^{73}$. Damit hatte der ReichsauBenminister den in Genf versammelten Politikern aller europäischer Staaten kundgetan, daß das Deutsche Reich nur durch laufende Erfüllung seines revisionspolitischen Gesamtprogramms saturiert werden könne. In einem Gespräch mit Briand erklärte Curtius seinem französischen Kollegen, die Zunahme der NSDAP sei auf „Versäumnisse des Auslands“ zurückzuführen und mit der baldmöglichsten Rückgliederung des Saargebiets müsse vor der Fortsetzung der deutsch-französischen Annäherung ein „Stein des Anstoßes" beseitigt werden; auch wandte er sich mit heftigen Worten gegen den Young-Plan ${ }^{74}$. Einige Wochen später sagte der Abgeordnete Pezet, ein Vertreter der katholischen Demokraten, in einer Debatte der Pariser Kammer, man habe zwar Vertrauen zu Brüning und seiner Regierung, aber eine Erfüllung der deutschen Revisionswünsche sei „unmöglich und gefährlich“; namentlich in der Korridorfrage könnten Deutschland keine Zugeständnisse gemacht werden ${ }^{75}$. Ministerpräsident André Tardieu schloß sich dem

71 Bülow an Curtius, 15. 9. 1930; PA, R 29505.

72 Hagemann, Deutschland am Scheideweg, S. VII.

73 Curtius an AA, 16. 9. 1930; PA, R 27977. Die Darstellung, die Curtius selbst gegeben hat (Sechs Jahre Minister, S. 171 f.), ist etwas geschönt.

74 Aufzeichnung Curtius, 18. 9. 1930; PA, R 29505.

75 Hoesch an AA, 7. 11. 1930; PA, R 70502. 
an und erklärte unzweideutig, daß jeder Versuch einer „Neuordnung der Grenzen Europas unfehlbar in Chaos und Krieg enden müßte"76. Sechs Tage darauf, am 20. November 1930, erwiderte Curtius im Reichsrat, es sei für die ganze Welt „eine notorische Tatsache, daß das deutsche Volk es nicht für möglich hält, sich mit dem gegenwärtigen Stand der Dinge, insbesondere im Osten einfach abzufinden“. Abermals sprach er von den „Lebensnotwendigkeiten unseres Volkes“. Ohne deren Berücksichtigung „wäre - das muß mit allem Ernst ausgesprochen werden - jede Hoffnung auf eine gedeihliche Zukunft nicht nur Deutschlands, sondern Europas verloren"77.

Die britische Regierung hatte Berlin wissen lassen, daß sie alles tun werde, um in Frankreich Briand und die von ihm repräsentierten Kräfte zu stützen, sofern ihr das die deutsche Regierung mit einer maßvollen und vernünftigen Politik ermögliche. Es sah aber gar nicht so aus, als sei die Reichsregierung dazu willens. In die Richtung, in die sie nationalsozialistischer Druck drängte, wollte sie ohnehin gehen, dabei freilich die Gangart selbst bestimmen. Noch war ihr Hitlers Erfolg gar nicht so unwillkommen, mußte er doch, was die Außenpolitik anging, in doppelter Hinsicht die Position des Kabinetts Brüning festigen: Erstens konnte nun in Verhandlungen über deutsche Forderungen die Existenz einer starken nationalistischen Opposition als Argument verwendet werden, zweitens durfte auf größeres Entgegenkommen der Gesprächspartner Deutschlands auch deshalb gerechnet werden, weil sie ein Kabinett Brüning naturgemäß immer noch sympathischer fanden als ein Kabinett Hitler. Ernst v. Weizsäcker gab sicherlich auch die Meinung seines Chefs wieder, als er im Dezember 1930 in einem Brief schrieb, die derzeitige patriotische Welle in Deutschland sei sogar die Vorbedingung, „um uns wieder ein Stück gegenüber dem Ausland vorzuschieben. Solange die Nazis nur randalieren und die Regierung zur politischen Aktivität treiben, ohne sie etwa zu stürzen, sollen sie mir als Folie willkommen sein... Die Schwierigkeiten für unser Amt bestehen nur darin, daß es die Angabe des Tempos nicht aus der Hand verlieren darf. "78 Curtius hatte denn auch nichts dagegen, wenn in das nationalistische Feuer noch weiteres Öl gegossen wurde. Am 5. Oktober 1930 fand in Koblenz eine große Kundgebung des „Stahlhelm“ statt, auf der einmal mehr derart chauvinistische Reden gehalten wurden, daß selbst die politischen und militärischen Kreise der Schweiz größte Nervosität zeigten und zum Beispiel, wie der Gesandte Adolf Müller aus Bern meldete, das Militärdepartment Kredite zum Ankauf von Gasschutzmaterial verlangte. Über diesen „Stahlhelmtag“ wurde ein Film gedreht, gegen dessen öffentliche Vorführung sogar Beamte des Auswärtigen Amts Bedenken erhoben. Der Minister teilte die Bedenken nicht ${ }^{79}$.

\footnotetext{
76 Ebenda.

77 WTB, 20. 11. 1930; PA, R 70502.

78 Weizsäcker-Papiere, S. 412.

79 Aufzeichnung Köpke, 13. 12. 1930; PA, R 70504.
} 
Andere kleine Vorfälle lassen ebenfalls erkennen, daß die Regierung sich schon auch aus eigenem Antrieb aktiver Revisionspolitik zu nähern gedachte, Vorfälle, die deshalb besonders aufschlußreich sind, weil die Öffentlichkeit von ihnen keine Kenntnis erhalten und daher mit ihnen nicht beeindruckt werden konnte; in ihnen kam die ureigene Gesinnung der Akteure unmittelbar zum Ausdruck. So wandelte sich - gelegentlich bereits vor den Wahlen - die Sprache mancher Diplomaten und auch die des Chefs der Zentrale, des Auswärtigen Amts. Wenn etwa mit dem litauischen Gesandten irgendein Memelproblem zu erörtern war, wurde nun Bülows Haltung strenger und seine Rede schärfer ${ }^{80}$, wenngleich er sich selbstverständlich nicht die Denkweise etlicher Führer der Memeldeutschen aneignete, die, wie Hans Ludwig Moraht, der Gesandte in Kowno, mitteilte, der Ansicht waren, „mit den Litauern müsse man nicht verhandeln, sondern man müsse sie anschnauzen und sie hinter die Ohren schlagen"81. Ein anderes Beispiel: Briand lag, wie man in Berlin sehr gut wußte, die Besserung der Beziehungen zwischen Reichswehr und französischer Armee am Herzen. Daher hatte er den Chef der Heeresleitung wiederholt darum bitten lassen, die bisher von den Manövern der Reichswehr ausgeschlossenen Militärattachés Frankreichs, Belgiens und Polens doch einzuladen. Die Heeresleitung hatte stets erwidert, das könne nicht in Frage kommen, solange deutsches Territorium von französischen und belgischen Truppen besetzt sei. Jetzt, nach der Rheinlandräumung, habe der General v. Hammerstein aber wiederum abgelehnt, so beklagte sich Briand Anfang September bei Hoesch; diesmal habe man als Grund genannt, daß die Stimmung im deutschen Offizierskorps dafür noch nicht reif sei. Müsse solche Verweigerung nicht als „geradezu tragisch" erscheinen ${ }^{82}$ ? Als zur gleichen Zeit der französische Geschäftsträger in eben dieser Angelegenheit Staatssekretär v. Bülow um Intervention bei der Heeresleitung bat, holte er sich ein kühles „Nein“83. Knapp zwei Wochen zuvor war der britische Botschafter zu Bülow gekommen, um ihm den Vorschlag zu unterbreiten, „kleine intime Frühstücke“ $z u$ veranstalten und so die Beziehungen zwischen deutscher Regierung und britischer Botschaft enger zu knüpfen; Sir Horace Rumbold hatte sich den Hinweis gestattet, wie nützlich doch das gute Verhältnis zwischen seinem Vorgänger Lord D'Abernon und deutschen Politikern gewesen sei. Mit dem Argument, die deutschen Gäste wollten dann britische Gastfreundschaft erwidern, seien aber aus finanziellen Gründen kaum dazu in der Lage, ließ Bülow das Angebot praktisch zu Boden fallen ${ }^{84}$. Nach einer Unterredung mit dem französischen Botschafter, während der Herr de Margerie, sicherlich kein überra-

80 Z. B. Aufzeichnung Bülow, 1. 9. 1930; PA, R 29449.

81 Mohrat an AA, 28. 8. 1930; PA, R 29513.

82 Hoesch an AA, 4. 9. 1930; PA, R 70502.

83 Aufzeichnung Bülow, 3. 9. 1930; PA, R 29449.

84 Aufzeichnung Bülow, 22. 10. 1930; PA, R 29449. 
gender Diplomat, wieder einmal pflichtgemäß die Beschwerden der Pariser Regierung über den frankophoben Zug der deutschen Politik vorgebracht hatte, was Bülow als „hochfahrend“ empfand und mit Härte zurückwies, schrieb der Staatssekretär an Hoesch: „Vielleicht finden Sie einmal eine Gelegenheit, dort maßgebenden Leuten anzudeuten, daß Margerie neben anderen Mängeln auch die Wahnvorstellung hat, er lebe noch in der Zeit der Ultimaten und der Kontrollkommission, und nicht der der Gleichberechtigung und Cooperation." 85 Ebenso charakteristisch war die Reaktion, als Stresemanns Witwe zu einem Vortrag über ihren Mann nach Paris fahren wollte. Gesandtschaftsrat Hans Riesser riet ihr, offenbar ohne Wissen seines Botschafters, dringend davon ab. Sie würde in Paris nur gegen die Nachfolger ihres Mannes „mißbraucht“ werden, hielt er ihr vor. Die Krönung der Arbeit Stresemanns sei die Rheinlandräumung gewesen: „Aber selbst er hätte niemals die politische Entwicklung hemmen können, die nach dieser Räumung innen- und außenpolitisch die gesamte Lage so tiefgreifend verändert hat." 86 Curtius und Bülow stimmten Riesser $\mathrm{zu}^{87}$.

Wichtiger war, daß die Reichsregierung sich daran machte, die Partei der revisionistischen Staaten gewissermaßen in eine Art Formation zu bringen, die gegenseitige Verständigung und Zusammenarbeit erleichtern sollte. Das geschah gewiß mit dem Blick auf alle revisionspolitischen Vorhaben, zunächst jedoch vor allem zur rechtzeitigen Rekrutierung von Bundesgenossen für die kommende Abrüstungskonferenz. Seit Gründung des Völkerbunds galt ja die Abrüstung als eine der bedeutendsten - sogar in der Satzung verankerten - Aufgaben der Genfer Institution. Die frühen Versuche bis Mitte der zwanziger Jahre waren zwar allesamt gescheitert, doch hatte der Völkerbundsrat am 12. Dezember 1925 eine „Vorbereitungskommission für die Abrüstungskonferenz" ins Leben gerufen, die sich im Mai 1926 an die Arbeit gemacht hatte und seither tatsächlich häufig tagte. Wohl brachte auch diese Kommission mitnichten hoffnungsvoll stimmende Resultate zuwege; mühselig genug schleppte sie sich von Sitzung zu Sitzung. Aber im Herbst 1930 stand immerhin fest, daß im kommenden oder im übernächsten Jahr eine große Abrüstungskonferenz stattfinden werde. Da Europa trotz Locarno nach wie vor in Verteidiger und Feinde des Status quo gespalten war, da insbesondere die italienisch-französischen Spannungen in beiden Ländern Anlässe zu großen - nicht zuletzt maritimen - Rüstungsanstrengungen lieferten und da mittlerweile Deutschland - einschließlich der Reichsregierung - unter heftigem Revisionsfieber litt, was wiederum Frankreich in permanente Furcht versetzte, konnte die Konferenz nicht unter einem guten Stern stehen. Dennoch wurde an der Fiktion,

85 Bülow an Hoesch, 29. 10. 1930; PA, R 29512.

86 Riesser an AA, 9. 2. 1931; PA, R 28698.

87 Eckel an Riesser, 9. 2. 1931; R 28698. 
Abrüstung sei nicht nur geboten, sondern auch erreichbar, weil doch alle Völker und Regierungen den guten Willen dazu hätten, vorerst festgehalten und eine sozusagen prinzipielle Zuversicht zur Schau getragen.

In den Augen der Reichsregierung bot die Abrüstungskonferenz vor allem die Chance, endlich die Entwaffnungsbestimmungen des Versailler Vertrags loszuwerden: Die Konferenz hatte zu scheitern und mit ihrem Scheitern Deutschland das Recht zur Aufrüstung zu verschaffen. Öffentlich ist das nie zugegeben, vielmehr entschieden bestritten worden. Als Generaloberst a.D. Hans v. Seeckt, von März 1920 bis Oktober 1926 Chef der Heeresleitung, im Herbst 1930 in einem Interview mit UP Aufrüstungsforderungen vertrat und trotzdem offenbar von Reichspräsident v. Hindenburg für geeignet gehalten wurde, Mitglied oder sogar Chef der deutschen Kommissionsdelegation zu werden, erklärte auch der amtierende Reichswehrminister, Generalleutnant a.D. Wilhelm Groener, solche Äußerungen als „verfrüht“, und Generalmajor Kurt v. Schleicher, Leiter des Ministeramts im Reichswehrministerium, schrieb an Otto Meissner, Staatssekretär im Präsidialamt, es sei doch „mißlich, eine Persönlichkeit mit der Vertretung der deutschen Interessen zu betrauen, die sich bereits öffentlich so festgelegt, und zwar in einer Richtung festgelegt hat, die unserem in Genf bisher vertretenen Standpunkt nicht in allen Punkten gleichläuft"; auch beherrsche Seeckt die freie Rede nicht besonders und sei ein schlechter Debatter. Und während Brüning den Generaloberst immerhin als „außerordentlichen militärischen Sachverständigen " in Erwägung ziehen wollte, lehnte das Auswärtige Amt Seeckt ebenfalls glatt $\mathrm{ab}^{88}$. In einer Chefbesprechung sagte Curtius am 30. Oktober 1930, im Augenblick halte er es nicht für zweckmäßig, „die deutsche Taktik zu wechseln, d.h. die Aufrüstung anzukündigen anstatt, wie bisher, die Abrüstung zu fordern“. An Stelle von „Aufrüstung“ müsse „Parität der Sicherheit“ verlangt werden. Jedoch trete er sehr wohl dafür ein, bei den Verhandlungen der Vorbereitungskommission „die deutsche Tonart“ wesentlich zu verschärfen; auch sei er durchaus gewillt, „alle tragbaren illegalen Rüstungsmaßnahmen zu decken"89. Groener pflichtete ihm bei: „die deutsche Sprache“ sei „bisher zu vorsichtig“ gewesen. Entscheidende Schritte aber sollten dann erst auf der Abrüstungskonferenz selbst getan werden. Im Moment durfte ohnehin nichts Konkretes geschehen, da, wie Reichskanzler Brüning sagte, 1931 vielleicht die Wendung gegen den Young-Plan einzuleiten sei und dabei eine zuvor geschehene Erhöhung der Rüstungsausgaben die deutsche Position schwächen würde. Curtius stellte dezidiert fest, 1931 gehöre der Reparationsfrage, 1932 der Rüstungsfrage ${ }^{90}$.

88 AdRK, Die Kabinette Brüning, Bd. 1., Nr. 158, mit Anm. 3 und 4.

89 AdRK, Die Kabinette Brüning, Bd. 1, Nr. 158.

90 Ebenda. 
Hingegen brauchte mit der Suche nach Bundesgenossen, die auf der Abrüstungskonferenz der deutschen Sache nützlich sein konnten, nicht gewartet $\mathrm{zu}$ werden. Curtius dachte dabei nicht zuletzt an die Vereinigten Staaten, da sich ja herausgestellt hatte, wie sehr die Regierung und die führenden Geschäftsleute der USA bei der im amerikanischen Interesse liegenden deutsch-französischen Annäherung auch Konzessionen Frankreichs für erforderlich hielten ${ }^{91}$. Ferner war es kein Geheimnis, daß viele einflußreiche Amerikaner, innerhalb und außerhalb der Regierung, wenig Geschmack an dem fanden, was sie als französischen „Militarismus“ ansahen, und die bisherige Unbeweglichkeit Frankreichs in der Abrüstungsfrage recht kritisch betrachteten; das mochte schwerer wiegen als die bis zum amerikanischen Unabhängigkeitskrieg und zur Französischen Revolution zurückreichende historische Verbundenheit beider Länder. So begann der deutsche Außenminister schon im Herbst 1930 mit dem Versuch, den amerikanischen Botschafter in Berlin, Frederic M. Sackett, zu bearbeiten und ihn - begleitet von Klagen über die Hegemonie Frankreichs in Europa - für Deutschlands Anspruch auf militärische Gleichtberechtigung zu erwärmen ${ }^{92}$.

Mit den sowjetischen Führern konnten indes bereits konkrete Absprachen getroffen werden. Zwischen Frühjahr 1930 und Mitte 1931 erreichte das gute politische Einvernehmen zwischen dem Deutschen Reich und der Sowjetunion wohl seinen zweiten - nach 1925/26 - Höhepunkt. In Moskau wurde mit tiefer Befriedigung registriert, daß die deutsche Regierung den Europaplänen Briands eine Absage erteilte, und zwar auch mit dem ausdrücklichen Hinweis auf das besondere deutsch-sowjetische Verhältnis, die Bedeutung der Sowjetunion in Europa und das sowjetische Mitspracherecht in europäischen Angelegenheiten ${ }^{93}$. Sowohl die öffentliche Aufwallung von Nationalismus und Revisionismus, die der Rheinlandräumung folgte, wie die revisionspolitisch begründete Rechtsdrift der Regierung Brüning sind, weil antipolnisch und antifranzösisch orientiert, von den Kremlherren nicht nur wohlwollend beobachtet, sondern nachdrücklich ermuntert worden. Die sowjetische Presse - u. a. Karl Radek in der "Iswestija“ - griff wieder und wieder die französische „Hegemonie“ auf dem europäischen Kontinent an und beschwor eine im Kampf gegen die Pariser Friedensverträge gege-

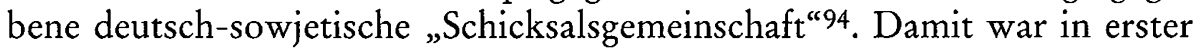
Linie die gemeinsame Polenfeindschaft gemeint, aber doch auch das ebenfalls gemeinsame Interesse an der allmählichen Auflösung der Kleinen Entente, die sozusagen im Solde der den Status quo sichernden französischen

91 Aufzeichnung Curtius, 5. 11. 1930; PA, R 27977.

92 Ebenda.

93 Andererseits warnte die sowjetische Presse bei Anzeichen deutsch-französischer Verständigung sofort, dass sich der "Weg nach Warschau über Paris“ als Illusion für Deutschland herausstellen wird. So Dirksen an AA, 12. 2. 1931; PA, R 28698.

94 Dirksen an AA, 18. 11. 1930; PA, R 70504. 
Hegemoniepolitik stand und einerseits die sudetendeutschen Territorien dem Deutschen Reich, andererseits Bessarabien der Sowjetunion vorenthielt; niemals, so sagte Maxim Litwinow, Volkskommissar für auswärtige Angelegenheiten, am 28. November 1930 zu Curtius, werde sich das russische Volk mit dem Verlust Bessarabiens abfinden ${ }^{95}$.

Auch im Hinblick auf die baltischen Länder kam es zu einer vorläufigen Verständigung. Eine im Sommer 1930 im Auswärtigen Amt entstandene Aufzeichnung über das sogenannte „Randstaatenproblem“ konstatierte, dieses Problem werde nach wie vor vom polnisch-russischen Gegensatz beherrscht: „Die polnische Politik erstrebt die Schaffung eines Nord-Südblocks von Finnland bis Rumänien unter polnischer (dem englischen oder französischen Einfluß mehr oder weniger unterworfener) Führung. Die russische Politik ging und geht dahin, die von Polen angestrebte Protektorrolle über die Randstaaten zu durchkreuzen und diese Staaten, zunächst unter Wahrung ihrer staatsrechtlichen Selbständigkeit, in politische und wirtschaftliche Abhängigkeit von der Sowjetunion zu bringen." Das deutsche Interesse, so schloß die Denkschrift, „liegt in der Linie der russischen Politik"96. Zur Debatte stand zwischen Berlin und Moskau vorerst die litauische Frage, da sich die Regierung Litauens gegen die Deutschen im Memelgebiet die in der Minderheitenpolitik aller Länder üblichen Torheiten (Sprache, Schule etc.) erlaubte und die Reichsregierung sich zum Schutz der Memeldeutschen verpflichtet fühlte; auch sollte das Memelland in absehbarer $\mathrm{Zu}$ kunft wieder zurückgewonnen werden. Die sowjetischen Führer warnten jedoch davor, Litauen durch übergroße Strenge in die Arme Polens zu treiben. Moskau werde die Litauer schon von einer allzu übermütigen Behandlung der Memeldeutschen abhalten. „Um des großen Zieles willen“, so sagte der sowjetische Botschafter in Berlin zu Bülow, müsse aber die Unabhängigkeit Litauens erhalten werden. Die Reichsregierung akzeptierte die sowjetischen Argumente und gestand damit stillschweigend ein, daß Litauen zur sowjetischen Interessensphäre gehöre ${ }^{97}$.

Die Erfolge der Nationalsozialisten sorgten auch in Moskau für Nervosität, und es zeichnete sich schon früh ab, daß die sowjetische Führung, sollte diese nicht allein Revisionismus, sondern eine deutsche „Raumpolitik“ predigende und daher in sowjetischen Augen brandgefährliche Bewegung in die Nähe der Macht oder an die Macht kommen, die Verbindung zu Polen und Frankreich suchen werde; im Oktober und November 1930 kam es zu ersten polnisch-sowjetischen Gesprächen über einen - dann 1932 tatsächlich abgeschlossenen - Nichtangriffspakt. Doch schienen im Herbst 1930 in Deutschland die revisionistischen Kräfte noch eindeutig zu dominieren,

95 Aufzeichnung Curtius, 28. 11. 1930; PA, R 70502.

96 Aufzeichnung Liedke, 30. 6. 1930; PA, R $28320 \mathrm{k}$.

97 Aufzeichnung Bülow, 3. 9. 1930, 10. 9. 1931; PA, R 29449. Ferner Dirksen an AA, 6. 8. 1930; PA, R $28305 \mathrm{k}$. 
schien eine auf Revisionspolitik festgelegte Regierung noch sicher im Sattel zu sitzen. So informierte Litwinow die deutschen Freunde loyal über die polnisch-sowjetischen Fühler und konnte dabei glaubwürdig versichern, daß sich am revisionistischen Kurs der Sowjetunion, also auch am besonderen Verhältnis zwischen Moskau und Berlin, nichts ändere ${ }^{98}$. Zwar sind im Auswärtigen Amt die Mitteilungen über den sowjetisch-polnischen Flirt doch nicht ganz ohne Eifersucht und momentanes Mißtrauen aufgenommen worden, aber das Vertrauen in die Festigkeit der deutsch-sowjetischen Verbindung blieb noch unerschüttert, und so hat die deutsche Seite allen Versuchen, Deutschland von der Seite der Sowjetunion wegzuziehen, auch dann widerstanden, wenn dabei mit Lockspeisen gearbeitet wurde.

Im Januar 1931 unterrichtete zum Beispiel Frédéric Hans v. Rosenberg, ehemals Außenminister, nun deutscher Gesandter in Stockholm, Bülow über eine Unterhaltung, die er mit Dr. Helmer Key gehabt hatte, dem Chefredakteur von „Svenska Dagbladet“: Key, gerade aus Frankreich zurückgekehrt, habe in Paris viele Franzosen gesprochen, die den lebhaften Wunsch nach einer antirussischen deutsch-französischen Allianz ausgedrückt und dies mit der Versicherung verbunden hätten, nach der Erledigung der Sowjetunion erledige sich doch das Problem der deutschen Ostgrenze von selbst99. Bülow, der zunächst geantwortet hatte, Rosenberg solle den Gedanken an die erwähnte Allianz nicht völlig abweisen, jedoch Gespräche darüber nicht vertiefen ${ }^{100}$, sagte dann aber wenige Tage später, bei solchen Avancen handle es sich lediglich um französische Bestrebungen, Deutschland von Rußland zu trennen: „Das kommt naturgemäß nicht in Frage."101 Als Bülow im Februar 1931 mit dem Genfer Bankier Hensch sprach, der einer Antibolschewistischen Liga vorstand und für den Bruch Deutschlands mit der Sowjetunion bei gleichzeitiger deutsch-französischer Verständigung plädierte, erklärte der Staatssekretär abermals dezidiert, ein Bruch mit Rußland sei ausgeschlossen ${ }^{102}$. Auf den von André François-Poncet, bald französischer Botschafter in Berlin, vorerst noch im Kabinett Unterstaatssekretär für die nationale Wirtschaft, nahezu gleichzeitig Hoesch gemachten Vorschlag, einfach den Berliner Vertrag mit der Sowjetunion nicht zu verlängern, ließ sich Bülow ebenfalls nicht ein ${ }^{103}$.

Tatsächlich gingen die Verhandlungen über die Verlängerung des Berliner Vertrags - am 24. Juni 1931 in Moskau unterzeichnet - glatt über die Bühne. Bemerkenswert war nur, wie deutlich die sowjetische Sorge vor einem wei-

${ }^{98}$ Dirksen an AA, 14. 7. 1931; PA, R 70505. - Dirksen an AA, 22. 12. 1931; PA, R 28306 k. Aufzeichnung Bülow, 10. 12. 1931; PA, R 29451. - Aufzeichnung Bülow, 28. 1. 1932; PA, R 29451.

99 Rosenberg an AA, 22. 1. 1931; PA, R 29514.

100 Bülow an Rosenberg, 26. 1. 1931; PA 29514.

101 Bülow an Rosenberg, 4. 2. 1931; PA, R 29514.

102 Aufzeichnung Bülow, 12. 2. 1931; PA, R $28306 \mathrm{k}$.

103 Hoesch an AA, 20. 2. 1931; PA, R 28306 k. 
teren Aufstieg der NS-Bewegung zum Ausdruck kam. Als Litwinow während einer Unterredung mit Herbert v. Dirksen, dem deutschen Botschafter in Moskau, sein Einverständnis erklärte, den Vertrag ohne Laufzeitbeschränkung abzuschließen, wollte er eine Klausel haben, die eine Kündigung frühestens nach fünf Jahren zuließ: „... auch in Erwägung, daß in den nächsten Jahren in deutscher Regierung und im Reichstag andere Mehrheit maßgebend sein könnte, die vielleicht der Sowjetregierung feindlich gesonnen wäre." 104 Noch herrschte indes Freundschaft, und der gemeinsame Revisionismus, auf dem die Freundschaft beruhte, knüpfte ein so festes Band, $\mathrm{daß}$ ihr etliche ernste Störfaktoren nichts anzuhaben vermochten: die unbefriedigende Entwicklung der Wirtschaftsbeziehungen; die Zunahme der Kommunistischen Partei in Deutschland; die Zementierung der Alleinherrschaft Stalins in Moskau, die mit den Anfängen einer gewaltsam durchgesetzten Kollektivierung der Landwirtschaft verbunden war, ebenso mit kirchenfeindlichen und antichristlichen Kampagnen, die Dirksen des öfteren rügte und auch Litwinow - hilflos - beklagte ${ }^{105}$. So konnte Anfang November 1930 zwischen Curtius und Litwinow in vertrauensvollem Gespräch die gemeinsame Taktik auf der kommenden Abrüstungskonferenz beraten werden, nämlich die „Isolierung Frankreichs und seiner Trabanten“ 106.

Ungarn warb, wie der deutsche Gesandte in Budapest, Hans v. Schoen, berichtete, jetzt ohnehin drängender um ein engeres Verhältnis zu dem außenpolitisch wieder beweglicher gewordenen und offenbar auch zur Nutzung der neuen Beweglichkeit entschlossenen Deutschen Reich. Als Graf Istvan Bethlen, der ungarische Ministerpräsident, Berlin besuchte, ebenfalls im November, machte es daher keine Mühe, sich gerade in der Abrüstungsfrage $\mathrm{zu}$ verständigen. Curtius und der ungarische Regierungschef versicherten einander die "Parallelität" der revisionspolitischen Interessen beider Länder, und auf die etwas besorgte Frage des deutschen Außenministers, ob dem die ungarisch-polnische Freundschaft nicht hinderlich sei, antwortete Graf Bethlen, diese Freundschaft gelte natürlich nicht gegen die deutschen Ansprüche an Polen ${ }^{107}$. Danach durfte man in Berlin ohne weiteres damit rechnen, das eigene Vorgehen auf der Abrüstungskonferenz mit dem ungarischen Verhalten taktisch abstimmen zu können.

Die Zusammenarbeit mit Italien hatte indes vorsichtig behandelt zu werden, gerade weil das italienische Interesse am deutschen und das deutsche Interesse am italienischen Revisionismus so klar zutage lag und daher angesichts der italienisch-französischen Spannung jede allianzartige Verbindung zwischen den beiden Staaten in Paris Alarm auslösen mußte. Deutschland war noch keineswegs so weit, sich eine solche Herausforderung Frankreichs

104 Dirksen an AA, 25. 3. 1931; PA, R $28306 \mathrm{k}$.

105 Dirksen an AA, 24. 3. 1931; PA, R 28306 k.

106 Aufzeichnung Curtius, 3. 11. 1930; PA, R 27977.

107 Aufzeichnung Curtius, 25. 11. 1930; PA, R 27977. 
erlauben zu dürfen, und in Italien konnte sich Mussolini zwar Frankreich bedrohende imperialistische Reden leisten, aber nicht einen militärischen Konflikt. Bülow betrachtete eine engere Verbindung mit Italien ohnehin skeptisch. Anfang November 1930 unterhielt sich Albert Freiherr Dufour von Feronce, ein deutscher Diplomat, der nun als Untergeneralsekretär des Völkerbunds amtierte, in Genf mit dem italienischen Justizminister Alfredo Rocco. Mussolini sei ein Freund der internationalen Gerechtigkeit, also der Revision der territorialen Zustände in Europa, sagte Rocco. Italien werde aufrüsten und sei sehr an der „Erstarkung Deutschlands“ interessiert; die Männer, die heute Italien regierten, seien ganz anders als die von 1914 und 1919. Bülow kommentierte das mit dem Satz, Roccos Redereien seien doch „reichlich phantastisch"108. Wenn Litwinow etwa um die gleiche Zeit zu Dirksen bemerkte, die Sowjetunion sei an guten deutsch-italienischen Beziehungen interessiert, aber nicht an einem Bündnis, da Italien für einen Krieg gegen Frankreich „zu schwach und zu arm“ sei109, so war das Bülow aus dem Herzen gesprochen. Er lehnte es denn auch ab, die Lancierung von Presseartikeln zu finanzieren, die eine deutsch-italienische Allianz propagieren sollten ${ }^{110}$. Die Bitte um Geld kam von Forstrat Escherich, der zur Zeit der Räterepublik in Bayern antikommunistische Heimwehren organisiert hatte, aus denen dann die 1921 auf Druck der Alliierten aufgelöste „Organisation Escherich“ (Orgesch) wurde; von 1929 bis 1933 war er Führer des „Bayerischen Heimatschutzes". Immerhin hatte Bülow nichts gegen eine informelle politische Kooperation zwischen Deutschland und Italien; schließlich gab es Felder mit gemeinsamen Interessen, zu denen Abrüstung und Abrüstungskonferenz gehörten. Und ein späteres Bündnis war ja auch nicht auszuschließen. So beschied er Escherich, die Werbung für ein deutsch-italienisches Bündnis sei „derzeit“ nicht tunlich, bewilligte ihm aber Geld für Artikel mit positiven Informationen über das faschistische System Italiens ${ }^{111}$.

Curtius brachte Italien gewiß mehr Wärme entgegen als Bülow, zumal er dem italienischen Außenminister Dino Grandi „auch menschlich näher gekommen war", wie er sagte ${ }^{112}$. In der Sache stimmte er jedoch mit Bülow durchaus überein. Die Presse der NSDAP agitierte zeitweilig für eine deutsch-italienische Allianz. Curtius hat entsprechende Absichten der Regierung stets dementiert, zwar mit Bedauern, wie er dem italienischen Botschafter erklärte, aber doch gezwungenermaßen: Auf Grund der „gemeinsamen Interessen“ würden die Beziehungen zwischen Rom und Berlin auch

108 Dufour-Feronce an Bülow, 4. 11. 1930; PA, R 29512.

109 Dirksen an Bülow, 9. 12. 1930; PA, R 29512.

110 Bülow an Escherich, 14. 7. 1930; PA, R 29465.

111 Ebenda. Bülow an Escherich über Überweisung von Geld, 11. 12. 1930; PA, R 29465.

112 Aufzeichnung Curtius, 25. 1. 1931; PA, R 27977. 
ohne Bündnis immer besser ${ }^{113}$. Es gab in Deutschland freilich nicht nur in der NSDAP Stimmung für ein enges deutsch-italienisches Zusammengehen. Kurz nach der Rheinlandräumung hatte der deutsche Gesandte in Bern, Adolf Müller, seinen Staatssekretär darüber informiert, daß höhere Reichswehroffiziere, die in die Schweiz abkommandiert seien oder sich aus anderen Gründen dort aufhielten, ihren „helvetischen Kameraden“ erzählten, wie sehr sie sich „auf einen gemeinsamen Feldzug mit Mussolini gegen Frankreich ... freuen“. Müller bat Bülow, dem Reichswehrminister Groener gelegentlich zu sagen, daß „er seine Herren etwas zur Vorsicht mahnen sollte"114. Bülow hat der Bitte sicherlich entsprochen, zumal er das Politisieren von Soldaten sowieso mißbilligte. Er hielt sie für politisch naiv und hat den bei General v. Hammerstein gelegentlich aufkeimenden Gedanken einer direkten Verständigung zwischen Reichswehr und französischer Armee - gar einer deutsch-französischen Militärallianz - stets sogleich zu ersticken gesucht: im Hinblick auf Polen und das deutsch-sowjetische Verhältnis, nicht zuletzt indes mit dem Blick auf die bevorstehende Abrüstungskonferenz. Hier sei so etwas auch taktisch falsch, „denn es wird nur dazu führen, daß man uns für ein billiges Trinkgeld die Handlungsfreiheit abknöpfen würde, die wir nach dem Scheitern der allgemeinen Abrüstungskonferenz wieder erlangen könnten "115. Nun lagen die Gedankenspiele Hammersteins weit neben den Realitäten der Beziehungen zwischen den beiden Armeen; da konnte nichts daraus werden. Vorzeitige Rodomontaden über ein noch gar nicht existierendes deutsch-italienisches Bündnis und über einen gemeinsamen Krieg gegen Frankreich konnten hingegen üble Wirkungen zeitigen und mußten folglich unterbunden werden.

Im übrigen sahen die italienischen Gesprächspartner von Curtius und Bülow die Dinge nicht anders als die deutschen Politiker. So meldete Schubert Anfang 1931 aus Rom, Grandi habe sich mit dem derzeitigen - lockeren, aber ausgezeichneten - Verhältnis zwischen Deutschland und Italien zufrieden erklärt. Der italienische Außenminister nutzte die von Schubert mitgeteilte Unterredung außerdem zu dem Versuch, der deutschen Regierung die Vorstellung zu vermitteln, daß es zwischen den italienischen Faschisten und den deutschen Nationalsozialisten, den bittersten Feinden des Kabinetts Brüning, keine Zusammenarbeit gebe: „Persönlich halte er von den HitlerLeuten und ihren außenpolitischen Zielen gar nichts. Was sie verkünden, halte er für Unsinn. "116 Im übrigen war auch in italienischen Augen der potentielle Bundesgenosse nicht stark genug. Die Zeit war noch nicht reif. Befriedigt konstatierte Bülow: „Es zeugt zweifellos von dem realen politischen

113 Aufzeichnung Curtius, 24. 11. 1930; PA, R 29513.

114 Müller an Bülow, 20. 7. 1930; PA, R 29513.

115 Bülow an Hoesch, 23. 1. 1931; PA, R 29514. Zitat in Bülow an Hoesch, 11. 11. 1930; PA, R 29512.

116 Schubert an Bülow und Curtius, 8. 1. 1931; PA, R 29514. 
Sinn Grandis, wenn er die übertriebenen Anbiederungen der Hitler-Leute als ,bêtises' ablehnt und sich mit der natürlichen Interessengemeinschaft bescheidet, die uns in manchen Fragen mit Italien verbindet." ${ }^{117}$

$\mathrm{Daß}$ in manchen Fragen tatsächlich eine natürliche Interessengemeinschaft bestand, machte man sich allerdings nun öfter gegenseitig klar, und allein schon damit eröffnete sich die Aussicht auf noch engere Beziehungen in der Zukunft. Im Februar 1931 bemerkte Grandi zu Schubert, derzeit sei eine deutsch-italienische Zusammenarbeit nur „im Rahmen von Genf“ zweckmäßig, eine darüber hinausgehende Zusammenarbeit „vorläufig nicht gut". Schubert sagte, er hoffe, daß die deutsch-italienische Zusammenarbeit auch in Zukunft weitergehen werde, und fügte "mit leisem Sarkasmus" hinzu: „natürlich im Rahmen von Genf“. Grandi erwiderte „lächelnd, man müsse in Bezug auf diese Zusammenarbeit, die im Anfangsstadium sei, noch vorsichtig vorgehen" 118 .

In Paris wurden die Indizien, die darauf hindeuteten, daß die ja schon im Frühjahr befürchtete deutsch-italienische Liaison vielleicht doch schon bald Realität werden könne, mit wachsender Sorge beobachtet. Konnte ein unberechenbarer Politiker wie Mussolini nicht zu einer Außenpolitik der Abenteuer verleitet werden? Konnte er womöglich die Scheu vor einem italienisch-französischen Krieg verlieren? Mitte November 1930 kam es zu einer Kammerdebatte, die Hoesch als ,treues Spiegelbild der ... Stimmungen und Beunruhigungen“ charakterisierte: „Im Mittelpunkt der tagelangen Diskussionen stand immer nur Deutschland... Die Kammerdebatte erweckte den Eindruck, als bestehe die gesamte französische Außenpolitik überhaupt nur in einem unmittelbaren oder mittelbaren Ringen gegen oder um Deutschland ..., und eine deutsch-italienische Verständigung erscheint als drohendes Gespenst."119

Zur gleichen Zeit machte Dr. Pfafferott, Rechtsbeistand der deutschen Botschaft in Paris, eine Aufzeichnung über eine Unterhaltung mit Edouard Pfeiffer, einem Radikalsozialisten mit engen Beziehungen zu Ministerpräsident Tardieu. Pfeiffer, der in sozusagen "offiziöser" Mission seiner Partei gekommen sei und Wert auf Weitergabe seiner Bemerkungen lege, habe zunächst konstatiert, daß in Frankreich das noch vor einem Jahr gegebene Vertrauen in die deutsche Politik inzwischen zum größten Teil geschwunden sei. Als Gründe habe er genannt: Das Ergebnis der Septemberwahlen, die chauvinistischen Manifestationen der deutschnationalen Verbände, das Eintreten offizieller deutscher Persönlichkeiten für den allgemeinen Revisionsgedanken und die bereits erkennbare Haltung Deutschlands in der Abrüstungsdebatte. Danach sei Pfeiffer auf Italien zu sprechen gekommen: Er

117 Bülow an Schubert, 13. 1. 1931; PA, R 29514.

118 Schubert an Curtius, 12. 2. 1931; PA, R 29514.

119 Hoesch an AA, 14. 11. 1930; PA, R 70502. 
und seine politischen Freunde seien auf die Möglichkeit gefaßt, daß Mussolini im März des nächsten Jahres den Auftakt zu kriegerischen Verwicklungen geben werde, und zwar durch provozierte Zwischenfälle an der jugoslawischen Grenze. Unter diesen Umständen, so habe er weiter erklärt, verfolge man mit besonderer Aufmerksamkeit die italienischen Versuche, Deutschland in einen italienisch-deutsch-russischen Block zu ziehen. Abrüstung sei daher zur Zeit unmöglich: „In internen Beschlüssen habe sich die Partei jeder Abrüstung im derzeitigen Augenblick widersetzt." Am Ende habe Pfeiffer den eigentlichen Zweck seines Besuchs enthüllt und gesagt, daß man in Frankreich die deutschen Kolonialwünsche nicht prinzipiell ablehne, anschließend sogar $\mathrm{zu}$ verstehen gegeben, daß bei Neutralität Deutschlands in einem französisch-italienischen Krieg selbst die Hinnahme des Anschlusses Österreichs und der Rückkehr des Korridors denkbar sei. Ganz deutlich sei der Satz gewesen: „Falls es zu einem französisch-italienischen Konflikt kommen sollte, und Deutschland sich bei dieser Gelegenheit des Korridors bemächtigen würde, würde Frankreich dies nicht als Kriegsfall Deutschland gegenüber ansehen." 120

Wie ernst solche Fühler genommen werden mußten, war mehr als fraglich, doch ließen sie erkennen, wie heftig die Kriegsfurcht Frankreich schüttelte. Auch der Aufgeregtheiten abholde Briand äußerte im März 1931 seine Besorgnis über Deutschlands Hinneigung zu Rußland, Italien und Ungarn ${ }^{121}$, zumal er aus einer Rede, die Curtius am 10. Februar im Reichstag gehalten hatte, mit Recht die Absicht der deutschen Regierung herauslas, bei einem für Deutschland unbefriedigendem Ergebnis der Abrüstungskonferenz aus dem Völkerbund auszutreten ${ }^{122}$.

Nun waren die Sowjetunion, das Deutsche Reich, Italien und Ungarn auch dann nicht zu aktiver territorialer Revisionspolitik fähig, wenn sie sich durch politische Fäden fester miteinander verbanden. Sie proklamierten Ziele, die sie noch immer nicht zu erreichen, und sie bekannten sich öffentlich zu Absichten, für deren Verwirklichung sie nach wie vor nichts zu tun vermochten. Die ebenfalls öffentliche Feststellung identischer Interessen und der dabei nicht selten mit feurigstem Pathos beschworene Wunsch nach gemeinsamem Handeln stürzten Europa in Unruhe und Kriegsfurcht, ohne daß sich an der Handlungsunfähigkeit etwas geändert hätte; es herrschte jetzt lediglich ein Zustand kollektiver Ohnmacht. Der Grund war wie bisher in der militärischen und folglich politischen Schwäche Deutschlands zu suchen. Politische Stärke kann es in zwei Fällen - über wirtschaftliche Kraft hinaus - nur bei militärischer Stärke geben: Wenn ein Nachbarstaat oder mehrere Nachbarn etwas ändern oder an sich reißen wollen, das man selbst 
für unaufgebbar oder unverzichtbar hält, sei es die Religion, die politische Kultur, die Freiheit, ein Territorium, und wenn man selbst ein Gut oder einen Besitz von Nachbarn begehrt, die diese unter keinen Umständen freiwillig zu opfern gedenken. Daß die territorialen Ansprüche der revisionistischen Staaten allein mit Androhung oder Anwendung militärischer Gewalt durchzusetzen waren, konnte nicht bezweifelt werden. Das galt für die Sowjetunion ebenso wie für Italien und Ungarn, erst recht aber für Deutschland, weil die Erfüllung der deutschen Forderungen das europäische Gleichgewicht völlig zerstören mußte.

In Berlin wußte das jedermann. Wer immer mit ausländischen Politikern, Diplomaten, Journalisten und Geschäftsleuten sprach, hörte - von wenigen Ausnahmen abgesehen -, daß Polen niemals mit friedlichen Mitteln zum Verzicht auf den Korridor, Westpreußen und Ostoberschlesien zu bewegen sei, von einem französischen Verzicht auf Elsaß-Lothringen ganz zu schweigen, und daß ein Konflikt mit Polen sogleich - auf Grund des französischen Eigeninteresses - Frankreich auf den Plan rufen werde. Mit der Reichswehr war jedoch, so wie sie sich 1930/31 darbot, eine militärische Abstützung territorialer Revisionspolitik gänzlich unmöglich. Sah Berlin seine Hände hinsichtlich der Verfolgung deutscher Wünsche gebunden, so sah es sich naturgemäß auch daran gehindert, den Vorreiter für die drei anderen Revisionisten zu machen. Tatsächlich hatte die Reichsregierung genau das eingeleitet, was Bülow als Anschluß an den italienischen Klub der "Blinden und Lahmen" verurteilte - und das, obwohl Deutschland selbst noch lahmte. Nur in einem Falle, der bald ins Spiel kommen sollte, glaubte die Regierung noch an die Brauchbarkeit politischer Rezepte. Ansonsten war sie im Hinblick auf die Territorialfragen zu politischer Ratlosigkeit verdammt. In solcher Lage drängte sich der Gedanke an Krieg nicht nur hitzigen Reichswehroffizieren auf, jedenfalls der Gedanke an Rüstung und die Wiedergewinnung militärischer Schlagkraft. Offensive Politik verlangte eine zur Offensive taugliche Armee, ob man die militärische Karte tatsächlich auf den Tisch schmettern mußte oder in der Hand behalten durfte.

In dieser Situation war es ebenso paradox wie zwangsläufig, daß die Reichsregierung, angetrieben von Entschlossenheit und geplagt von Hilflosigkeit, eine weitere revisionspolitische Forderung aufs Tapet brachte, für deren Realisierung sie ebenfalls noch keine politische Konzeption und keinen taktischen Gedanken hatte. Bereits Ende August 1930 hatte Reichsminister Treviranus in der „Berliner Börsenzeitung“ einen Artikel veröffentlicht, der eine wilde Kampfansage an den Young-Plan darstellte. Der Entwurf zu diesem Artikel war im Auswärtigen Amt entstanden, doch hatte Treviranus den Text erheblich verschärft ${ }^{123}$. Tatsächlich war er, obwohl der Plan ja in ganz Europa als Provisorium galt und das Kabinett Brüning 
durchweg aus Kritikern des Plans bestand, vorgeprescht, hatte er sich etwas zu früh und etwas zu kämpferisch geäußert. Doch sollte es nicht lange dauern, bis die Regierung in den sozusagen öffentlich versandten Katalog ihrer revisionistischen Wünsche auch die Revision des Young-Plans aufnahm. Ende September 1930, während der 61. Tagung des Völkerbundsrats, machte Curtius gegenüber Briand eine entsprechende Andeutung, und obwohl der französische Außenminister sofort warnte, so kurz nach Unterzeichnung des Plans sei doch nicht gleich dessen Revision möglich ${ }^{124}$, ließ sich die Regierung nicht mehr stoppen. Am 16. Oktober kündigte Reichskanzler Brüning im Reichstag noch etwas verklausuliert die Wendung gegen den Young-Plan an ${ }^{125}$, und am 22. Oktober richtete Bülow an die deutschen Botschaften in London und Paris die Frage, wie die britische beziehungsweise die französische Reaktion wäre, wenn Deutschland Zahlungsaufschub verlangen oder Zahlungseinstellung verkünden sollte ${ }^{126}$. Hoesch antwortete sofort, daß das Aufwerfen des Reparationsproblems unweigerlich zu einer Bewegung gegen Briand führen würde, eine Erörterung glatter Einstellung der Zahlungen sogar zur Forderung nach Wiederbesetzung des Rheinlands. Es käme das Argument, Deutschland habe sich die Annahme des Young-Plans mit der Räumung des Rheinlands bezahlen lassen, nur um dann sogleich die Verpflichtungen des Plans abstreifen zu wollen. Das würde in Frankreich als „Illoyalität“ gelten; die verheerende Wirkung auf den deutschen Kredit habe er, Hoesch, ja schon bei seinem letzten Aufenthalt in Berlin dargelegt ${ }^{127}$.

Von Hoeschs negativer Stellungnahme - und von zahlreichen anderen frühen Warnungen vor einer Schädigung des deutschen Kredits - offensichtlich unbeeindruckt, zitierte Curtius am 27. Oktober erst den britischen und dann den französischen Botschafter zu sich, um ihnen zu eröffnen, daß Deutschland möglicherweise bald in die Lage gerate, gegen den Young-Plan vorgehen zu müssen ${ }^{128}$. Daß Curtius an ein und demselben Tag die Botschafter der beiden Hauptgläubiger solchermaßen informierte, gab seinem Schritt ernste Bedeutung und stempelte das Wörtchen "möglicherweise“ zur bloßen Floskel, zumal Reichspräsident v. Hindenburg sich einen Tag danach, und zwar ebenfalls in einem Gespräch mit dem französischen Botschafter, genauso äußerte wie der Außenminister ${ }^{129}$. Curtius setzte die Serie derartiger Mitteilungen am 20. November im Reichsrat fort ${ }^{130}$, und am 1. Januar 1931 stellte beim Neujahrsempfang der Reichsregierung Brünings

124 Aufzeichnung Bülow, 27. 9. 1930; PA, R 29465.

125 Schulthess', 1930, S. 208 f.

126 Bülow an Missionen in Paris und London, 22. 10. 1930; PA, R 27977.

127 Hoesch an Bülow, 25. 10. 1930; PA, R 27977.

128 Aufzeichnung Curtius, 27. 10. 1930; PA, R 27977.

129 Aufzeichnung Meissner, 28. 10. 1930; PA, R 70502.

130 WTB., 20. 11. 1930; PA, R 70502. 
Vertreter Groener vor dem versammelten Diplomatischen Corps die vielsagende „Frage ..., ob das deutsche Volk die in dem Neuen Plan vorgesehenen Lasten zu tragen vermag“. Die Reichsregierung sei sich „ihrer Pflicht bewußt, dafür zu sorgen, daß die sittlichen und sozialen Lebensgrundlagen des deutschen Volkes nicht erschüttert werden"131.

Außerhalb Deutschlands begegnete die Ankündigung eines Generalangriffs auf den Young-Plan herber Kritik. Eine nicht geringe Rolle spielte dabei der Eindruck, daß die Regierung Brüning ihre Politik mehr und mehr von den Pressionen der Deutschnationalen und Nationalsozialisten bestimmen lasse. Schon kleine Vorfälle sind in diesem Sinne gedeutet worden, so als nach dem öffentlichen Krawall eines vom Berliner Gauleiter Joseph Goebbels geführten nationalsozialistischen Mobs der auf dem Buch von Erich Maria Remarque basierende Film „Im Westen nichts Neues“ verboten wurde. Sir Horace Rumbold kommentierte seine Mitteilung über den Erfolg nationalsozialistischen Randalierens mit der Bemerkung, die Schwäche der Reichsregierung habe „nicht dazu beigetragen, den durchschnittlichen und ordnungsliebenden Bürger zu beruhigen "132. Als besonders verstörendes Symptom registrierte der Botschafter: „Jüdische Bankiers, die im Gesellschaftsleben von Nachkriegsberlin eine immer größere Rolle gespielt hatten, haben in diesem Winter bislang überhaupt keine Einladungen mehr gegeben. Das mag zum Teil auf die ernste Wirtschaftslage zurückzuführen sein, die viele von ihnen getroffen hat. Doch ist es auch, davon bin ich überzeugt, eine Folge der Angst vor nationalsozialistischen Angriffen. "133 Erst recht konstatierten nichtdeutsche Beobachter einen Effekt nationalsozialistischen Drucks, wenn sie sahen, wie gleichsam die Regierungsgeschütze auf den Young-Plan einschwenkten. Größten Schrecken löste dabei die sichere Erwartung aus, daß Aktionen der Reichsregierung gegen den Plan die deutsche Wirtschaft schwer erschüttern würden, was bei der krisenhaften Entwicklung der Weltwirtschaft üble Auswirkungen auf ganz Europa haben mußte.

Die schärfste Kritik - verbunden mit einer präzisen Prognose der Konsequenzen deutscher Ungeduld - kam von Arthur Henderson, dem britischen Außenminister. „Mit aller Entschiedenheit möchte ich feststellen“, so schrieb er an Sir Horace Rumbold, „daß, nach Meinung der Regierung Seiner Majestät, die derzeitige finanzielle und wirtschaftliche Lage Deutschlands die deutsche Regierung in keiner Weise dazu berechtigt, darauf hinzuweisen, es könne notwendig werden, ein Moratorium zu erklären... Im Gegenteil. Die Regierung Ihrer Majestät vertritt die Ansicht, daß eine solche Aktion im Hinblick auf die schwerwiegenden wirtschaftlichen und politi-

131 Groener, 1. 1. 1931; PA, R 28035.

132 Rumbold an Henderson, 5. 1. 1931, DBFP, Second Series, Vol. I, Nr. 344.

133 Ebenda. 
schen Folgen, die sie haben muß, aufs schärfste zu mißbilligen ist." Die wirtschaftlichen Schwierigkeiten Deutschlands existierten unabhängig vom Young-Plan. Die unmittelbare Wirkung einer Moratoriumsforderung werde „höchstwahrscheinlich darin bestehen, das Vertrauen ausländischer Geldgeber völlig zu zerstören“. Man müsse sich daran erinnern, „daß die Drohungen der Hitler-Leute den Kredit Deutschlands, der in den vergangenen fünf Jahren so mühsam und mühselig wiederhergestellt worden ist, ernstlich erschüttert haben und ihn gänzlich ruiniert hätten, wären die Ängste, die diese Äußerungen weckten, nicht durch die feste Politik beruhigt worden, die von der Deutschen Regierung bislang verfolgt worden ist. Sollte nun der Anschein entstehen, daß die Deutsche Regierung diese Haltung aufgegeben und sich einer Politik ergeben hat, die von den Extremisten diktiert ist, so würde es mit ziemlicher Sicherheit zum vorzeitigen Abzug ausländischer Anleihen und zur Einstellung weiterer Kredite aus dem Ausland kommen, während in Deutschland die Tendenz zur Flucht aus der Mark sich unweigerlich verstärken müßte.“ Daraus könne sehr wohl „ein vollständiger Zusammenbruch des deutschen Wirtschaftssystems resultieren"134. Der britische Botschafter setzte Curtius und Bülow am 10. Dezember 1930 in Kenntnis der Epistel aus London. Vom Anfang bis zum Ende der Unterhaltung sei „die Atmosphäre ausgesprochen freundlich“ gewesen - „... es ist doch ein Vorzug, mit einem Manne [d.h. Curtius] solch ruhigen und ausgeglichenen Temperaments zu tun zu haben" $" 135$.

Indes übten die Mahnungen und Prophezeiungen aus London nicht den mindesten Einfluß auf die Reichsregierung aus. Auch die Warnungen der eigenen Fachleute prallten an dem Mann ab, der jetzt, zusammen mit seinen engsten Mitarbeitern, in der Reparationspolitik das Steuer übernahm. Hielt sich Reichskanzler Brüning in anderen außenpolitischen Fragen eher zurück, zwar nicht die Zielsetzung, wohl aber die Wahl des Vorgehens und die Leitung der Geschäfte Kabinettskollegen und vor allem dem Auswärtigen Amt überlassend, so war das beim Problem Young-Plan schlechterdings nicht möglich. Zu eng hing die Reparationspolitik mit der Finanz- und Wirtschaftspolitik, im weiteren Sinne mit der gesamten Innenpolitik der Regierung zusammen. Angesichts dieser Verschränkung war die Behandlung des Young-Plans notwendigerweise Chefsache, ganz unabhängig von Brünings persönlicher Neigung, die den Finanzpolitiker freilich ebenfalls zur bestimmenden Rolle in der Reparationspolitik drängte. Und Brüning ließ die Londoner Stimmen ebenso unbeachtet wie die sorgenvollen Einwände des Reichsbankpräsidenten Hans Luther oder des Staatssekretärs im Finanzministerium Hans Schäffer, wie sie Brünings Staatssekretär Hermann Pünder etwa nach einer Besprechung am 6. März 1931 in seinem Tagebuch 
festhielt ${ }^{136}$. Auch nach einer Konferenz, die am 23. April 1931 stattfand, notierte Pünder zur Diskussion über eine Attacke gegen den Young-Plan: „Die Zünftigen sind sehr dagegen..."137

Brüning war in finanzpolitischen Dingen ein gewiegter Experte und sah daher durchaus, daß die Kritik der Fachleute ins Schwarze traf. Wenn er sie trotzdem ignorierte, so lag das daran, daß ihn, als er sich gegen den YoungPlan zu wenden begann, nicht eigentlich die schlechte finanzielle und wirtschaftliche Situation Deutschlands motivierte, wie er - zusammen mit der ganzen Reichsregierung - alsbald behaupten sollte, und daß ihm eine weitere Verschlechterung, statt ihn zu schrecken, durchaus willkommen war. Ohne daß er in seinem ersten Amtsjahr schon eine klarere Vorstellung gehabt hätte, wie operativ und taktisch vorzugehen sei, begriff er schnell, daß die Krise und ihre laufende Verschärfung irgendwann die einzigartige Chance bieten mußte, die gesamte Reparationslast mit einem Ruck abzuwerfen - und diese Entlastung hielt er für absolut notwendig, wenn auch weniger aus finanziellen und wirtschaftlichen Gründen. Gewiß machte es die Krise nicht gerade leichter, die Annuitäten des Young-Plans aufzubringen, weshalb von der Wirtschaftslage schon ein gewisser Druck zur Reform des Plans ausging. Doch wußte Brüning so gut wie Henderson, daß die Nöte der deutschen Wirtschaft nicht von den Reparationszahlungen verursacht wurden und daß die wirtschaftliche Erholung nicht von der Streichung der Reparationsschuld abhing.

Tatsächlich fühlten sich Brüning und seine Mitarbeiter im Ablauf der Dinge sogar unter Zeitdruck: Was sollte geschehen, wenn sich die Situation der Wirtschaft besserte, ehe man die Reparationen losgeworden war? Entscheidend waren vielmehr zwei andere Antriebselemente. Brünings Politik der Deflation und des ausgeglichenen Haushalts, von ihm zur Behauptung der Währungsstabilität als unvermeidlich erachtet, zwang bei dem rapide fortschreitenden wirtschaftlichen Niedergang fortwährend zu harten Sparmaßnahmen und produzierte damit unentwegt Arbeitslose und Elend; so mutete sie großen Teilen der deutschen Bevölkerung eine schier unerträgliche Belastung zu. Das verlangte nach einem Ausgleich, der nicht allein in Versprechungen für die Zukunft bestehen konnte. Kampf gegen die Reparationen hingegen mochte als ein solcher Ausgleich wirken. Das wies der $\mathrm{Na}-$ tion ein Ziel, in dessen Namen zu Anstrengungen aufgerufen und die Hinnahme eines gerüttelten Maßes an Entbehrungen als nationale Pflicht deklariert werden konnte. Reichspräsident v. Hindenburg entschlüpften solche moralischen Appelle gelegentlich in Gestalt militärischer Vergleiche, so als er auf dem Höhepunkt der Kampagne gegen den Young-Plan einmal in öffentlicher Rede sagte, während der Schlacht bei Tannenberg seien auch 
Schwierigkeiten aufgetreten, hätten ebenfalls „hohe Anforderungen an die Truppe“ gestellt werden müssen ${ }^{138}$. Staatssekretär Pünder drückte das ziviler aus, als er noch vor Beginn der Kampagne in sein Tagebuch schrieb: „Immer weiter drosseln ohne Reparationsreform, das zerreißt unser armes Volk völlig." 139

Eine derartige Verknüpfung der Finanz- und Wirtschaftspolitik mit der Reparationsfrage bot im übrigen den zusätzlichen Vorteil, daß die Reparationslast, je hitziger über sie geredet und gegen sie gefochten wurde, mehr und mehr als die Ursache der wirtschaftlichen Kalamitäten erschien, ihre Abschüttelung mithin das Ende von Not und Elend verhieß. Noch größere Bedeutung besaß in Brünings Augen jedoch sicherlich die Überlegung, daß die Wiedergewinnung der finanziellen Bewegungsfreiheit erforderlich war, um die von der kommenden Abrüstungskonferenz zuversichtlich erwartete militärische Gleichberechtigung und Rüstungsfreiheit auch ausnützen zu können. Daß dem Reparationsproblem Priorität zukomme, stand fest, da nach einer spürbaren Erhöhung der militärischen Ausgaben die Gläubigerstaaten niemals einer Verringerung oder gar Streichung der Reparationsschuld zustimmen würden. Wie Curtius sagte: das Jahr 1931 gehört der Reparationsfrage, das Jahr 1932 der Rüstungsfrage ${ }^{140}$.

Eine brauchbare Taktik bot sich jedoch nicht ohne weiteres an. Das größte Hindernis stellte eine die Reichsregierung offenbar überraschende, ihr jedenfalls höchst lästige Hilfsbereitschaft der Gläubiger dar. Als Hindenburg Botschafter de Margerie bedeutete, Deutschland werde, wenn sich auch nach drastischen Sparmaßnahmen die Erfüllung der Reparationsverpflichtung als unmöglich erweise, an die Gläubigerstaaten herantreten müssen, antwortete de Margerie ohne Zögern: „Dann, wenn trotz der Ersparnisse und der Ausgabeneinschränkung sich die Unmöglichkeit der Erfüllung ... herausstellte, würde niemand Deutschland das Recht bestreiten, in neue Verhandlungen einzutreten, und man würde sich auf diese Unterhandlungen mit gutem Willen einlassen." 141 Eine Woche später sprach Henry Moysset, Tardieus Kabinettschef, ganz unbefangen über eine etwaige Revision des Young-Plans ${ }^{142}$, und am 13. November 1930 hielt Briand in der Pariser Kammer eine Rede, in der er nicht nur, wie Hoesch schrieb, sich „in mutigen und überzeugten Worten zur Annäherungspolitik mit Deutschland" bekannte, "die er auch in Zukunft fortzusetzen fest entschlossen sei“, sondern überdies mitfühlende Worte über die Not in Deutschland mit dem Wink verband, daß Erleichterungen in der Reparationsfrage durchaus möglich seien: „Minister wurde“, so Hoesch, „fast von gesamter Kammer mit

138 Schulthess', 1930, S. 274.

139 Pünder, Politik in der Reichskanzlei, S. 93.

140 AdRK, Die Kabinette Brüning, Bd. 1, Nr. 158.

141 Aufzeichnung Meissner, 28. 10. 1930; PA, R 70502.

142 Müller an AA, 5. 11. 1930; PA, R 70502. Moysset hielt sich gerade in der Schweiz auf. 
Ausnahme Kommunisten und äußersten rechten Flügels mit lebhaftem Beifall begrüßt und erntete zum Schluß ebenfalls stürmische Beifallskundgebungen größten Teils der Kammer." 143

Derartige Freundlichkeiten fanden Brüning und seine Mitstreiter gar nicht erfreulich, vielmehr irritierend, weil für die eigene Zielsetzung gefährlich. Das französische Entgegenkommen wurde ja unter der Voraussetzung offeriert, daß Deutschland seine Reparationsverpflichtung grundsätzlich weiter anerkenne und nur eine partielle wie temporäre Erleichterung suche. Noch war Frankreich keineswegs bereit, Deutschland die volle finanzielle Bewegungsfreiheit zuzugestehen. Die Furcht vor deutscher Revanche saß dafür viel zu tief. In der Tat war das Mißtrauen, das Deutschland entgegengebracht wurde, für die französischen Politiker das eigentliche Motiv, sich am Young-Plan festzuklammern, weit stärker als die so oft ins Feld geführte Unentbehrlichkeit der deutschen Gelder zur Rückzahlung der amerikanischen Kriegskredite; das sollte sich im Ablauf der Dinge ganz deutlich zeigen. Brüning hingegen wollte nicht eine vorübergehende Minderung der Reparationslast, sondern ihre vollständige Liquidierung. So konnte sich der Kanzler, was er dem Auswärtigen Amt und dem Kabinett wieder und wieder klarlegte, auf kein allzu frühes Moratorium einlassen ${ }^{144}$. Solange sich die deutsche Wirtschaftslage nicht dramatisch verschlechterte, würden die Gläubigerstaaten zwar Konzessionen machen, aber lediglich einer Teillösung zustimmen, die dann, sollte sie von der Reichsregierung akzeptiert werden, einem erneuten Angehen des Reparationsproblems sogar im Wege stehen mußte.

Die Verschärfung der Wirtschaftskrise, erst als Chance begriffen, erwies sich - in Brünings Augen und auch, wie wohl festzustellen ist, tatsächlich binnen kurzem, kaum hatte man angefangen, ernsthaft über die Möglichkeiten eines Angriffs auf den Young-Plan nachzudenken, als die unerläßliche Voraussetzung erfolgreicher Reparationspolitik. Jedenfalls durfte die französische Hilfsbereitschaft nicht zur Kenntnis genommen werden, glaubte sich die Reichsregierung noch etliche Zeit zu Passivität genötigt, gleichsam zu einer Taktik rein negativer Art. Wie bei den territorialen Fragen auch, schuf die deutsche Regierung selbst in der Reparationsfrage durch drohende Absichtserklärungen Unruhe in Europa, ja - angesichts der globalen Wirkung internationaler Finanzpolitik - in der ganzen Welt, ohne politische Schritte folgen zu lassen. Allein schon damit gab die Regierung des Deutschen Reiches zu erkennen, daß sie - wiederum wie bei den territorialen Ansprüchen - sich nicht mit hemmenden Teillösungen begnügen, sondern im geeigneten Augenblick eine Politik des "Alles oder Nichts" verfolgen werde. Allerdings war zunächst auch für den passenden Moment noch völ-

144 So z. B. ein Schreiben Pünders, im Auftrag Brünings, an Bülow, 3. 1. 1931; PA, R 29467. 
lig offen, was dann eigentlich zu geschehen habe. Wohl sah der Young-Plan selbst vor, daß Deutschland bei Zahlungs- oder Transferschwierigkeiten eine internationale Expertenkommission anrufen solle, um sich die Schwierigkeiten bestätigen zu lassen. Jedoch schien diese Kommission, nahm man den Plan streng beim Wort, lediglich befugt, die zeitweilige Einstellung der sogenannten „geschützten“ Annuitäten vorzuschlagen, und nicht in der Lage, den Young-Plan als Ganzes in Frage zu stellen. Wie Pünder im Februar 1931 notierte: „Die Behelfe des Young-Plans sind nicht viel wert, deshalb soll man sie nicht anwenden, aber trotzdem sie als Kugeln in der Flinte oder als Pappschwert in der Metallscheide politisch verwerten." 145 Aus einem solchen Satz sprach Ratlosigkeit. Man wollte eine Politik des „Alles oder Nichts", hatte für sie indes noch keine Konzeption. 